\title{
Analytical modelling of plastic collapse in compressed elliptical hollow sections
}

\author{
A. Insausti ${ }^{1}$ and L. Gardner ${ }^{2}$ \\ 1 Visiting academic, Imperial College London, UK \\ 2 Reader in Structural Engineering, Imperial College London, UK
}

\begin{abstract}
The plastic collapse response of structural steel elliptical hollow section (EHS) profiles in compression is examined in this paper. As an initial step, a parametric study to identify the factors that determine which plastic mechanisms would arise has been carried out using finite element (FE) results from the current work and experimental data from the literature. All investigated EHS had a cross-sectional aspect ratio of two. The parametric study revealed four plastic collapse mechanism and showed that the "split flip disc" plastic collapse mechanism is the most likely to appear in compressed EHS. Thus, the present work is focussed on this failure mechanism, for which an analytical model to describe the relationship between load and deformation is developed. Coupled with consideration of the elastic, yielding and strain hardening characteristic of the steel, the derived analytical model enables construction of the full load-deformation behaviour of compressed EHS to be establish. The parameters controlling the shape and size of the plastic hinges have been investigated and found to be of key importance; hence, special care has been taken in their definition. Finally, the developed load-displacement curves have been compared with both finite element results and experimental data. The comparisons have revealed good agreement, confirming the ability of the analytical model to predict the collapse response of elliptical tubes.
\end{abstract}

\section{Keywords}

Analytical modelling; Compression; Elliptical hollow sections; Finite element modelling; Local buckling; Numerical modelling; Oval hollow sections; Plastic collapse; Plastic mechanism; Steel structures. 


\section{Notation}

a half larger outer dimension of elliptical cross-section

b half smaller outer dimension of elliptical cross-section

$D_{e} \quad$ equivalent diameter of elliptical cross-section

dN differential axial load

ds differential arc length along surface of elliptical section

E Young's modulus

$\mathrm{E}_{\text {sh }} \quad$ slope of strain hardening regime

$\mathrm{f}_{\mathrm{LB}} \quad$ local buckling stress

$\mathrm{f}_{\mathrm{y}} \quad$ yield stress

L stub column length

$\mathrm{M}_{\mathrm{pl}} \quad$ full plastic moment

$\mathrm{M}_{\mathrm{pl}}^{\prime} \quad$ reduced plastic moment in presence of axial load

$\mathrm{M}_{\mathrm{pl}} \quad$ reduced plastic moment in presence of axial load on inclined hinge line

$\mathrm{N} \quad$ axial load

$\mathrm{N}_{\text {in }} \quad$ force inside plastic mechanism

$\mathrm{N}_{\text {out }}$ force outside plastic mechanism

$\mathrm{s} \quad$ arc length along surface of elliptical section

$\mathrm{S}_{\mathrm{h}} \quad$ width of plastic mechanism on the surface of elliptical section

$\mathrm{S}_{\mathrm{h}, \mathrm{a}}$ final width of plastic mechanism on the surface of elliptical section once the mechanism is fully formed

$\mathrm{S}_{\text {out }}$ arc length along surface outside the plastic mechanism

$\mathrm{t}$ thickness of elliptical cross-section

w width of rectangular element of material

$\mathrm{X}_{\mathrm{h}} \quad$ height of plastic mechanism

$\mathrm{X}_{\mathrm{h}}{ }^{\prime} \quad$ height of plastic mechanism up to the point of zero bending moment

$\beta \quad$ angle between inclined hinge line and the direction of thrust

$\Delta \quad$ maximum lateral displacement of hinge

$\Delta_{\mathrm{ds}} \quad$ maximum lateral displacement of material strip within plastic mechanism

$\Delta^{\prime} \quad$ straight distance between the point of zero bending moment and the undeformed position

$\delta \quad$ end shortening of stub column

$\delta_{\max } \quad$ axial deformation corresponding to peak load 
$\varepsilon_{\mathrm{LB}} \quad$ local buckling strain

$\varepsilon_{\text {sh }} \quad$ strain at the onset of strain hardening

$\varepsilon_{\mathrm{y}} \quad$ yield strain

$\lambda_{\text {EHS }}$ slenderness of elliptical cross-section

$v \quad$ Poisson's ratio 


\section{Introduction}

Hot-finished structural steel elliptical hollow sections (EHS) have recently been introduced to the construction sector. These structural elements can offer greater structural efficiency than circular hollow sections (CHS) when subjected to bending or combined loading, or when used as columns with intermediate restraint about the weaker axis, since they posses different major and minor axis flexural properties. Despite recent investigations involving the testing, numerical modelling and development of design rules for EHS, a number of aspects of their structural response remain unexplored. In particular, the behaviour of elliptical profiles in the post ultimate region has not yet been examined. Besides defining the unloading branch of the load-deformation curve, an accurate description of this region also allows the possibility of quantifying the ductility of the system.

The aim of the present work is to develop an analytical model to predict the full loaddeformation response of EHS under pure compression. Towards this end, rigid plastic theory has been applied to elliptical profiles based on the method presented by Murray for plates [1]. Hence, equations relating the applied axial load to the characteristic lateral displacement of the plastic mechanism, as well as to the end shortening of the member, have been derived.

As an initial step, and with reference to the responses of flat plates and circular hollow sections, which represent the bounds to the behaviour of elliptical sections, a parametric study was carried out to identify the most common local plastic collapse mechanisms arising in EHS. The study, described in Sections 3 and 4 of this paper, involved finite element modelling and the analysis of existing test data [2]. Whilst a number of failure modes were identified, an inward plastic collapse mechanism of the form shown in Fig. 1 was the most prominent. An analytical description of this collapse mechanism is therefore the focus of the present study. Development and calibration of the rigid plastic analytical model to describe the unloading behaviour of compressed EHS is described in Sections 5 of the paper. Once the load-displacement curve was derived, the key parameters controlling the size and shape of the hinge lines in the plastic mechanism were carefully examined and their influence on the unloading behaviour was assessed. The full load-deformation response was 
subsequently assembled in Section 6 by introducing the elastic loading, yielding and strain hardening components, the extent of which were dictated by the cross-section deformation capacity, which itself was determined from a derived relationship with cross-section slenderness. In Section 7, comparisons between the analytical model and results obtained from both the FE models and existing tests are discussed.

\section{Literature review}

The intermediate response of elliptical tubes between that of flat plates and circular shells has been previously identified in terms of elastic buckling [3] and post-buckling [4]. In anticipation of an analogous scenario for plastic collapse, previous studies on rigid plastic mechanisms in flat plates and circular shells are initially reviewed herein. For rigid plastic mechanisms in flat plates, early pioneering work was carried out by Murray [1], who introduced a number of different failure modes and derived corresponding load-deformation relationships. Among the common plate-like patterns identified, the so called "flip disc" mechanism was presented in detail. This mechanism is formed by two parabolic hinge lines, one of them folding outwards and the other one inwards, creating a disc shape plate within the hinge lines that flips around the horizontal mid axis. A further collapse pattern referred to as the "roof type" mechanism was also identified. The roof type mechanism includes two outer straight hinge lines and a further straight hinge line at mid-mechanism together with four inclined hinge lines [1]. Ultimate behaviour of flat plates was found to be sensitive to the pattern of failure; Mahendran [5] showed that the type of mechanism that arose in thin compressed plates is governed by the location of the first yield point, and provided plate slenderness and initial imperfection limits to define the failure mechanism. Further research showed that both the flip disc and roof type mechanisms are commonly present in compressed square hollow sections (SHS) [6] and fabricated box sections $[7,8]$, and comparisons between these mechanisms and the mechanisms in flat plates [9] have been made.

Research on compressed CHS identified two main local plastic failure modes - the "elephant foot" and "Yoshimura" mechanisms. The elephant foot mode is an axissymmetrical mode with outwards deformation that creates a concertina shape in the surface, while the Yoshimura pattern includes several sequential folding lines that 
deform the cross-section in a non axis-symmetrical way. The boundaries that define the occurrence of each plastic failure mode were studied by Andrews et al. [10] by means of compression tests involving annealed aluminium cylindrical tubes. Both failure modes, as well as a mixed mode, were identified in the experimental work and a classification chart to predict their occurrence was developed. Later, the available experimental data on compressed CHS were expanded by Guillow et al. [11] carrying out more tests on annealed aluminium tubes over a wider cross-section slenderness range. As a consequence, a revised chart for the classification of CHS plastic mechanisms was developed. For the elephant foot mode, load-displacement curves were derived by Grzebieta [12] using the plastic mechanism approach. Further experimental results on circular tubes specifically proportioned to develop axissymmetric failure modes were presented by Gupta and Velmurugan [13] while Johnson et al. [14] studied the Yoshimura type mechanism by means of tests involving circular PVC tubes.

The key difference between the elements previously studied (i.e. flat plates and CHS) and EHS lies in the continuously varying curvature brought about by the following geometrical definition:

$$
\frac{\mathrm{z}^{2}}{\mathrm{a}^{2}}+\frac{\mathrm{y}^{2}}{\mathrm{~b}^{2}}=1
$$

where the symbols are defined in Fig. 2. There is no exact analytical expression to determine the perimeter of an ellipse, but the approximation of Ramanujan [15] is commonly used. However, in the present study, rather than the entire perimeter, the arc length of a specific interval is required to describe the hinge lines in the plastic mechanism. An approximate numerical approach is employed herein, as described in Section 5 .

The earliest research into elastic buckling of oval hollow sections (OHS) was conducted by Marguerre in 1951 [16]. Some years later Kemper [17] concluded that the elastic buckling stress of an OHS could be obtained using the expression for CHS with the maximum radius of curvature of the oval, and that this solution was a lower bound. This proposal was considered later by Hutchinson [18] who stated that it could also be applied to EHS provided the section is thin. Between 1964 and 1968, Kemper 
and Chen studied the post buckling behaviour of OHS [19-21] concluding that sections with low aspect ratios (similar to CHS) exhibit less stable post buckling behaviour while sections with higher aspect ratios (similar to plates) present more stable post buckling behaviour. This conclusion was verified experimentally by Tennyson et al. [22].

With the recent introduction of hot-finished EHS into the construction sector, renewed interest in the structural behaviour of elliptical profiles, as well as the need to develop design guidance, have emerged. Structural performance data have been generated on elliptical sections in compression [2, 23] and bending [24]. The result of the 25 compression tests (stub column tests) given in [2], together with numerically generated results, have been used in the present study for the development and validation of the analytical model. The outer dimensions of the tested cross-sections ranged from $150 \times 75$ to $500 \times 250 \mathrm{~mm}$, all with a cross-sectional aspect ratio of two. The length of the members was chosen so as to avoid member buckling. Based on the results of the compression and bending tests $[2,24]$ and an analysis of the elastic buckling of EHS, a cross-section slenderness parameter was derived for the purpose of cross-section classification [25]. The slenderness parameter was based on an equivalent diameter $D_{e}$, which allowed the classification of EHS to be made on the basis of the CHS slenderness limits. For the case of pure compression the equivalent diameter $D_{e}=2 a^{2} / b$; this corresponds to the point in the section with maximum radius of curvature, $\mathrm{a}$ and $\mathrm{b}$ being half the larger and smaller outer dimensions respectively of the EHS, as shown in Fig. 2. This point of the section was identified by Kemper [17] and Hutchinson [18] as the point of initiation of buckling and as suitable for use with the classical formula for CHS in determining elastic buckling stresses for EHS. More precise expressions for determining the equivalent diameter have also been derived $[3,26]$, while an alternative approach to classification of EHS, based on an equivalent rectangular hollow section (RHS), was proposed in [23].

Flexural buckling of EHS columns has been investigated by Chan and Gardner [27], who performed 24 tests and concluded that the buckling curves for hot-finished CHS may be safely applied to hot-finished EHS. Concrete filled EHS have also been examined [23, 28, 29], and it was found that the capacity expressions for concretefilled RHS may be safely applied to EHS. This approach was shown to be slightly 
conservative since greater confinement is afforded to the concrete by an EHS tube than by an RHS tube. EHS connections have been studied by [30] and [31], and design rules for end slotted connections proposed.

\section{Finite element modelling}

\subsection{Introduction}

In this section, finite element analysis is used to examine the plastic collapse behaviour of stocky EHS in compression. The models have already been validated against a total of 25 compression tests [2], where they were shown to be capable of replicating the full load-end shortening curves. Although the experiments provided load-end shortening data, lateral displacement representing local buckling and the formation of a plastic collapse mechanism was not measured; thus, the FE models were used to generate this information. Moreover, the FE models provided useful information of the shape of the plastic hinge during the deformation process that has been used to derive the analytical model. Further to this, the validated FE models were also used to identify the different plastic collapse mechanisms arising for different section geometries and in the presence of different imperfections. Hence, it has been possible to focus the research on the more commonly arising plastic collapse modes.

\subsection{Basic modelling features}

All models were developed using the nonlinear finite element software ABAQUS. The elements designated as S4R in ABAQUS were employed throughout the modelling. These elements are four-noded reduced integration shells with six degrees of freedom per node and are suitable for thick and thin applications [32]. A uniform mesh size of $2 \mathrm{a} / 10^{(\mathrm{a} / \mathrm{b})} \times 2 \mathrm{a} / 10^{(\mathrm{a} / \mathrm{b})}$ was employed, with maximum element sizes of $20 \times 20 \mathrm{~mm}$.

The cross-sectional dimensions of the modelled elliptical sections were kept constant at $150 \times 75 \mathrm{~mm}$, while eight variations of thickness $-2,2.4,3,3.75,4,5,6.3$ and $8 \mathrm{~mm}$ - were considered, providing a range of cross-section slenderness values. The member length was fixed at $300 \mathrm{~mm}$, which was sufficiently short to ensure no global buckling, and all sections were subjected to concentric compression. All models were 
assigned rigid plastic material properties without strain hardening or residual stresses, to allow direct comparison with the analytical model developed in Section 5. The modified Riks method was employed to enable the unloading behaviour of the studied profiles to be traced.

\subsection{Boundary conditions and initial imperfections}

To represent the test boundary conditions [2] and to ensure that failure occurred away from the column ends, all degrees of freedom were fixed at both ends of the columns, other than longitudinal displacement at the loaded end. The initial geometrical imperfection shapes used in the nonlinear analyses were generated from prior elastic buckling analyses of the same EHS. The lowest elastic buckling modes were closely spaced and three of them, which were symmetrical about the cross-section centreline (i.e. the $x-z$ plane), were considered as initial imperfections. These initial imperfections were classified with respect to their symmetry about the mid-height of the member - "symmetrical" corresponding to an odd number of half-wavelengths along the member length and a non-zero displacement at mid-height and "asymmetrical" corresponding to an even number of half-wavelengths along the member length and zero displacement at mid-height - and as either positive (inwards at mid-height) or negative (outwards at mid-height). Thus, the three imperfections considered were: (a) symmetrical positive, (b) symmetrical negative and (c) asymmetrical (positive and negative being equivalent). In addition three variations of the imperfection amplitude $-t, t / 10$ and $t / 100$ - were considered. Hence, a total of nine variations of initial imperfection were applied to the each EHS studied, giving a range of plastic collapse modes that are discussed in Section 4.

\section{Identification of plastic collapse mechanisms in EHS}

\subsection{Introduction}

According to plastic theory, the number of possible plastic mechanisms in a thinwalled structure is unlimited; however, some plastic failure patterns are more commonly repeated when the element is loaded in a specific way. The present section discusses the trend of the elliptical profiles to follow specific failure mechanisms with reference to the FE and test results. Hence, the more common local plastic failure modes in EHS can be identified and focussed upon in the analytical study. 


\subsection{Plastic mechanisms observed in the FE models}

The variation of the initial geometrical imperfections described in the previous section triggered four different plastic failure modes, two of them akin to plate-like behaviour and the other two akin to shell-like (CHS) behaviour - see Fig. 3. Within the platelike failure modes, one of them is similar to the flip disc (FD) mechanism examined by Murray [1] for flat plates, while the other is a variation of it. This variation includes an extra straight hinge line (when projected onto the x-z plane) in the middle of the mechanism splitting the disc in two half parts as shown in Fig. 1 (experimentally) and Fig. 3b (numerically). This plastic mechanism is referred to herein as the "split flip disc" (SFD) mechanism. The shell-like plastic collapse mechanisms observed in the EHS are the elephant foot (EF) and the Yoshimura (Y) patterns. All four mechanisms are shown in Fig. 3.

The specific failure mode that a given EHS profile would succumb to was found to be influenced by both the shape and amplitude of the initial geometric imperfection, as well as the slenderness $\left(D_{e} / t\right.$, where $\left.D_{e}=2 a^{2} / b\right)$ of the cross-section. Fig. 4 presents the plastic failure modes that arose in the FE models with the different shapes and level of initial imperfection amplitude and varying cross-section slenderness.

The graphs show that plate-like failure modes dominate the profile's behaviour for the smaller (and more practical) levels of initial imperfection. Indeed, the $t / 10$ and t/100 imperfection amplitude zones are mainly occupied by flip disc or split flip disc mechanisms, which are inward failure modes. Among the plate-like failure modes, a symmetrical positive imperfection tends to create both flip disc and split flip disc responses while the symmetrical negative imperfection triggered only split flip disc pattern. Fig. 4 also shows that the elephant foot mode only arises with small initial imperfections and the Yoshimura pattern does not feature in the range of scenarios covered in the figure. For larger imperfections, the Yoshimura mode appeared in the presence of a symmetrical positive imperfection shape. Thus, it can be concluded that the flip disc and split flip disc modes arise most commonly when the most practical imperfection sizes are employed, while the elephant foot mode occurs for small initial imperfections and the Yoshimura mode is only present when very large initial imperfections are used. 
According to [1], plastic collapse mechanisms can be classified as either true or quasi mechanisms. A true mechanism can be developed from the original element by folding along the plastic hinge lines only with no extensional deformation of the material. A quasi mechanism, on the other hand, involves both folding along the hinge linen and material stretching or contraction. The FE models revealed that neither the flip disc nor the split flip disc mechanisms present any significant extensional deformation and are thus true mechanisms, while the elephant foot mode involves significant circumferential stretching of the material along the outer ring and is thus a quasi mechanism.

\subsection{Plastic mechanisms observed in the experimental work}

The experimental work presented in [2] has also been used to identify the plastic failure mechanisms arising in compressed EHS. The tests exhibited three of the four modes revealed in the numerical study: the flip disc, the split flip disc and the elephant foot modes. However, the elephant foot was present only in four out of 25 tests. The flip disc and the split flip disc modes appeared in the remaining 21 tests in no clear pattern; overall, the split flip disc mechanism appeared more frequently, though it was difficult to distinguish between these two mechanisms in many cases. The Yoshimura mode was not observed in the tests.

Summing up, four different plastic collapse mechanisms have been identified in compressed EHS, two of them being similar to plate-like modes - the flip disc and split flip disc mechanisms - and two of them similar to shell-like modes - the elephant foot and Yoshimura mechanisms. The most commonly arising mode in both the experimental and numerical studies was the split flip disc mode, hence, development of an analytical description of this plastic failure mechanism is the focus of this paper.

\section{Analytical modelling}

\subsection{Introduction}

In this section, an analytical model for the split flip disc mode arising in compressed EHS is developed based on the plastic theory for thin-walled structures presented by Murray [1]. As stated by Murray, assuming that the material stress-strain curve is a step function with a step height between tensile and compressive yielding of $2 f_{y}$, 
where $f_{y}$ is the material yield strength, a cross-section's load-carrying capacity can be derived from equilibrium as a function of the displacement, based on an assumed plastic collapse mechanism. Rigid plastic material behaviour is therefore used, which neglects strain hardening, and all deformation is assumed to be localised along the hinge lines with no deformation elsewhere. This assumption has been shown to be reasonable for the split flip disc mode in the previous section, where it was also observed that the plastic mechanism did not extend around the full circumference of the cross-section. Thus, in the analytical derivation, the load resisted both within the plastic mechanism $\mathrm{N}_{\text {in }}$ and outside the plastic mechanism $\mathrm{N}_{\text {out }}$ are considered - see Sections 5.2 and 5.3, respectively.

The moment capacity of a plastic hinge, based on a rectangular element of material of width $w$ and thickness $t$ is given by:

$$
\mathrm{M}_{\mathrm{pl}}=\frac{\mathrm{f}_{\mathrm{y}} \mathrm{w} \mathrm{t}^{2}}{4}
$$

The reduced plastic moment $\mathrm{M}_{\mathrm{pl}}^{\prime}$ in the presence of an axial load $\mathrm{N}$ may be shown to be:

$$
M_{p l}^{\prime}=M_{p l}\left(1-\left(\frac{N}{f_{y} w t}\right)^{2}\right)
$$

Eq. 3 applies when the hinge line is perpendicular to the direction of the applied thrust. However, for an inclined hinge line, the reduced plastic moment is given by Eq. 4 , where $\beta$ is the angle between the line perpendicular to the thrust and the inclined hinge line [1].

$$
M_{p l}^{\prime \prime}=M_{p l}^{\prime} \sec ^{2} \beta
$$

In the present work, both parabolic and elliptical functions were considered for the description of the curved hinge lines in the plastic mechanism. However, the parabolic hinge lines were found to more accurately replicate the actual load-displacement response of EHS. Thus, this shape is used throughout the present derivation. A parabola can be defined using two parameters that fix the height $X_{h}$ and the width $S_{h}$ 
of the curve on the surface of the EHS (Eq. 5). The notation employed in this section is illustrated in Fig. 5, together with the definition of the angle $\beta$ (used in Eq. 4).

$$
x(s)=X_{h}\left(1-\left(\frac{s}{S_{h}}\right)^{2}\right)
$$

The load transmitted by the complete cross-section can be obtained in terms of the load inside the plastic hinges $\mathrm{N}_{\text {in }}$ plus the load outside the plastic hinges $\mathrm{N}_{\text {out }}$. Furthermore, by using symmetry, only one quarter of the cross-section needs to be analysed with the result for the full cross-section being factored accordingly. The contribution to the load-carrying capacity of the cross-section from within the hinge lines and outside hinge lines are derived in the following two sub-sections.

\subsection{Load-carrying contribution within the plastic hinges}

Since the inclination of the hinge lines is variable around the cross-section, a differential strip of material is analysed, as depicted in Fig. 5, with the following reduced plastic moment.

$M_{p l}^{\prime \prime}=\frac{f_{y} t^{2}}{4}\left(1-\left(\frac{d N}{f_{y} t d s}\right)^{2}\right) \sec ^{2} \beta d s$

in which $\mathrm{dN}$ is the load in the strip and ds is the strip width.

The differential arc length ds along the curved hinge lines can be obtained from Eq. 1, by setting $\mathrm{z}=\mathrm{a} \cos \theta$, as:

$\mathrm{ds}=\sqrt{\mathrm{a}^{2} \sin ^{2} \theta+\mathrm{b}^{2} \cos ^{2} \theta} \mathrm{d} \theta$

Fig. 6 presents the free body diagram of the material strip that relates the lateral displacement of the strip $\Delta_{\mathrm{ds}}$ to the applied load $\mathrm{dN}$ and the reduced plastic moment $\left(\mathrm{M}_{\mathrm{pl}}^{\prime}\right.$ for the plastic hinge lines perpendicular to the line of thrust and $\mathrm{M}_{\mathrm{pl}}^{\prime}$ for the inclined plastic hinge lines). The load borne by the strip $\mathrm{dN}$ can be related to the lateral displacement by considering equilibrium at a null bending moment point. For the split flip disc mechanism, the point of zero bending moment lies between the 
curved hinge line and the straight hinge line that splits the flip disc into two equal parts. Fig. 7 presents the bending moment diagram in the strip. Denoting $\Delta^{\prime}$ the straight distance between the point of zero bending moment and the undeformed position, this distance can be related to $\Delta_{\mathrm{dS}}$ through the lengths $\mathrm{X}_{\mathrm{h}}$ and $\mathrm{X}_{\mathrm{h}}{ }^{\prime}$, which are defined in Fig. 7. Hence, $\Delta^{\prime}$ may be written as a function of the magnitudes of $\mathrm{M}_{\mathrm{pl}}^{\prime}$ and $\mathrm{M}_{\mathrm{pl}}$, and consequently as a function of the plastic hinge inclination $\beta$ :

$$
\left.\begin{array}{l}
\frac{\Delta_{\mathrm{dS}}}{\Delta^{\prime}}=\frac{\mathrm{X}_{\mathrm{h}}}{\mathrm{X}_{\mathrm{h}}^{\prime}} \\
\frac{\mathrm{X}_{\mathrm{h}}}{\mathrm{X}_{\mathrm{h}}^{\prime}}=\frac{\mathrm{M}_{\mathrm{pl}}^{\prime}+\mathrm{M}_{\mathrm{pl}}^{\prime \prime}}{\mathrm{M}_{\mathrm{pl}}^{\prime \prime}}
\end{array}\right\} \Delta^{\prime}=\Delta_{\mathrm{dS}} \frac{\mathrm{M}_{\mathrm{pl}}^{\prime \prime}}{\mathrm{M}_{\mathrm{pl}}^{\prime}+\mathrm{M}_{\mathrm{pl}}^{\prime \prime}}=\Delta_{\mathrm{dS}} \frac{\sec ^{2} \beta}{1+\sec ^{2} \beta}
$$

By considering moment equilibrium about the point of zero bending moment (defined by $\Delta^{\prime}$ ), the load borne by the strip $\mathrm{dN}$ may be related to $\mathrm{M}_{\mathrm{pl}}^{\prime}$ and $\mathrm{M}_{\mathrm{pl}}^{\prime \prime}$ as follows:

$\mathrm{dN} \Delta^{\prime}=\mathrm{M}_{\mathrm{pl}}^{\prime \prime}=\mathrm{M}_{\mathrm{pl}}^{\prime} \sec ^{2} \beta$

Merging Eq. 8 and Eq. 9, introducing the reduced plastic moment of the material strip (Eq. 6) and rearranging, we obtain:

$\mathrm{dN}=\mathrm{f}_{\mathrm{y}} \mathrm{t}\left(\sqrt{\left(\frac{2 \Delta_{\mathrm{ds}}}{\left(1+\sec ^{2} \beta\right) \mathrm{t}}\right)^{2}+1}-\frac{2 \Delta_{\mathrm{ds}}}{\left(1+\sec ^{2} \beta\right) \mathrm{t}}\right) \mathrm{ds}$

The lateral displacement of the strip $\Delta_{\mathrm{dS}}$ at any point around the section can be related to the maximum lateral displacement of the hinge $\Delta$ through Eq. 11, where $x(s)$ defines the parabolic shape of the curved hinge lines (Eq. 5). This relationship is also illustrated in Fig 8.

$$
\Delta_{\mathrm{ds}}=\Delta \frac{\mathrm{x}(\mathrm{s})}{\mathrm{X}_{\mathrm{h}}}=\Delta\left(1-\frac{\mathrm{s}^{2}}{\mathrm{~S}_{\mathrm{h}}^{2}}\right)
$$

At the same time, Eq. 5 may be manipulated to give the following expression:

$$
\left(\frac{\mathrm{dx}}{\mathrm{ds}}\right)^{2}=4 \frac{\mathrm{X}_{\mathrm{h}}^{2}}{\mathrm{~S}_{\mathrm{h}}^{4}} \mathrm{~s}^{2}
$$


And hence

$1+\sec ^{2} \beta=2+\tan ^{2} \beta=2+4 \frac{X_{h}^{2}}{S_{h}^{4}} s^{2}$

From Eqs. 10, 11 and 13, and following some further manipulation, we obtain the load carried by each strip as:

$d N=f_{y} t\left(\sqrt{\left(\frac{S_{h}^{2}\left(S_{h}^{2}-s^{2}\right) \Delta}{\left(S_{h}^{4}+2 X_{h}^{2} s^{2}\right) t}\right)^{2}+1}-\frac{S_{h}^{2}\left(S_{h}^{2}-s^{2}\right) \Delta}{\left(S_{h}^{4}+2 X_{h}^{2} s^{2}\right) t}\right) d s$

Eq. 14 can not be integrated explicitly; hence, in the present work Simpson's rule has been employed to obtain the load-lateral displacement curve, as advised in [1]. The load in the strip was evaluated at 3 points: $\mathrm{s}=0, \mathrm{~s}=\mathrm{S}_{\mathrm{h}} / 2$ and $\mathrm{s}=\mathrm{S}_{\mathrm{h}}$.

$\mathrm{dN}(\mathrm{s}=0)=\mathrm{f}_{\mathrm{y}} \mathrm{t}\left(\sqrt{\frac{\Delta^{2}}{\mathrm{t}^{2}}+1}-\frac{\Delta}{\mathrm{t}}\right)$

$\mathrm{dN}\left(\mathrm{s}=\frac{\mathrm{S}_{\mathrm{h}}}{2}\right)=\mathrm{f}_{\mathrm{y}} \mathrm{t}\left(\sqrt{\frac{9 \mathrm{~S}_{\mathrm{h}}^{4} \Delta^{2}}{4\left(2 \mathrm{~S}_{\mathrm{h}}^{2}+\mathrm{X}_{\mathrm{h}}^{2}\right)^{2} \mathrm{t}^{2}}+1}-\frac{3 \mathrm{~S}_{\mathrm{h}}^{2} \Delta}{2\left(2 \mathrm{~S}_{\mathrm{h}}^{2}+\mathrm{X}_{\mathrm{h}}^{2}\right) \mathrm{t}}\right)$

$\mathrm{dN}\left(\mathrm{s}=\mathrm{S}_{\mathrm{h}}\right)=\mathrm{f}_{\mathrm{y}} \mathrm{t}$

Thus, using Eqs. 15, 16 and 17 with Simpson's rule and rearranging, the following relationship (Eq. 18) between load carried within the plastic hinges $\mathrm{N}_{\text {in }}$ and lateral displacement $\Delta$ of the split flip disc mechanism for one quarter of the section is obtained.

$\mathrm{N}_{\text {in }}=\frac{\mathrm{f}_{\mathrm{y}} \mathrm{t} \mathrm{S}_{\mathrm{h}}}{6}\left(1-\frac{\Delta}{\mathrm{t}}-\frac{6 \mathrm{~S}_{\mathrm{h}}^{2} \Delta}{\left(2 \mathrm{~S}_{\mathrm{h}}^{2}+\mathrm{X}_{\mathrm{h}}^{2}\right) \mathrm{t}}+\sqrt{\frac{\Delta^{2}}{\mathrm{t}^{2}}+1}+4 \sqrt{\frac{9 \mathrm{~S}_{\mathrm{h}}^{4} \Delta^{2}}{4\left(2 \mathrm{~S}_{\mathrm{h}}^{2}+\mathrm{X}_{\mathrm{h}}^{2}\right)^{2} \mathrm{t}^{2}}+1}\right)$

The relationship is governed by the parameters $X_{h}$ and $S_{h}$, which define the shape of the plastic mechanism. These parameters are examined in Section 5.4. 
For the flip disc mechanism, which, unlike the split flip disc mechanism, does not contain a central hinge line, the load carried within the plastic mechanism $\mathrm{N}_{\text {in }}$ can be obtained as:

$$
\mathrm{N}_{\text {in }}=\frac{\mathrm{f}_{\mathrm{y}} \mathrm{t} \mathrm{S}_{\mathrm{h}}}{6}\left(1-\frac{2 \Delta}{\mathrm{t}}-\frac{6 \mathrm{~S}_{\mathrm{h}}^{2} \Delta}{\left(\mathrm{S}_{\mathrm{h}}^{2}+\mathrm{X}_{\mathrm{h}}^{2}\right) \mathrm{t}}+\sqrt{\frac{4 \Delta^{2}}{\mathrm{t}^{2}}+1}+4 \sqrt{\frac{9 \mathrm{~S}_{\mathrm{h}}^{4} \Delta^{2}}{4\left(\mathrm{~S}_{\mathrm{h}}^{2}+\mathrm{X}_{\mathrm{h}}^{2}\right)^{2} \mathrm{t}^{2}}+1}\right)
$$

If the previous derivation for the split flip disc mechanism were to be repeated with elliptical hinge lines (Eq. 20) instead of parabolic hinge lines (Eq. 5), the expression for $\mathrm{N}_{\text {in }}$ presented in Eq. 21 results.

$$
\begin{aligned}
& x(s)=X_{h} \sqrt{1-\frac{s^{2}}{S_{h}^{2}}} \\
& N_{\text {in }}=\frac{f_{y} t_{h}}{6}\left(1-\frac{\Delta}{t}-\frac{12 \sqrt{3} S_{h}^{2} \Delta}{\left(6 S_{h}^{2}+X_{h}^{2}\right) t}+\sqrt{\frac{\Delta^{2}}{t^{2}}+1}+4 \sqrt{\frac{27 S_{h}^{4} \Delta^{2}}{\left(6 S_{h}^{2}+X_{h}^{2}\right)^{2} t^{2}}+1}\right)
\end{aligned}
$$

\subsection{Load-carrying contribution outside the plastic hinges}

The area of the cross-section outside the plastic hinges is considered to be working at the yield stress. Hence, the load-carrying contribution from outside the plastic hinges is proportional to the arc length outside the hinge $\mathrm{S}_{\text {out }}=\mathrm{P} / 4-\mathrm{S}_{\mathrm{h}}$, where $\mathrm{P}$ is the perimeter of the ellipse, and is given for one quarter of the section as:

$$
\mathrm{N}_{\text {out }}=\mathrm{f}_{\mathrm{y}} \mathrm{t}\left(\frac{\mathrm{P}}{4}-\mathrm{S}_{\mathrm{h}}\right)
$$

The total load carried by the full cross-section is obtained from Eq. 18 and Eq. 22 as:

$$
\mathrm{N}(\Delta)=4\left(\mathrm{~N}_{\text {in }}+\mathrm{N}_{\text {out }}\right)
$$

\subsection{Parameters controlling the shape of the plastic mechanism}

Since the load-carrying capacity of the section depends on the shape of the plastic mechanism, $X_{h}$ and $S_{h}$ must be defined in order to determine the final load-lateral displacement curve. At this point, information obtained from the FE models and the 
tests has been used to monitor the value of both parameters in different elliptical tubes, but with a constant aspect ratio $a / b=2$. The results showed that, under increasing deformation, the plastic hinges grew towards a constant value once the plastic mechanism was fully formed. The constant (final) values of $X_{h}$ and $S_{h}$ are considered first, after which expressions that describe the changing nature of the plastic hinge (i.e. $X_{h}$ and $S_{h}$ as a function of the lateral displacement) are introduced. This section presents the analytical curves obtained using both constant and variable plastic hinge dimensions, and compares them with the FE results.

The longitudinal wavelength for elastic buckling of CHS (in the axis-symmetric mode) is proportional to $\sqrt{\mathrm{Dt}}$ where $\mathrm{D}$ is the diameter and $\mathrm{t}$ is the thickness of the section [3]. Clearly the elastic buckling wavelength is influential in the definition of the size of the plastic collapse mechanism. Hence, the measured values of $\mathrm{X}_{\mathrm{h}}$ at the end of the plastic deformation from the FE models and the experiments have been plotted against $\sqrt{D_{e} t}$ in Fig. 9, where $D_{e}=2 a^{2} / b$ is the equivalent diameter of the EHS. The data may be seen to follow an approximately linear trend, and hence Eq. 24 was obtained by least squares regression, ensuring that the line passes through the origin, and used in the analytical model.

$$
\mathrm{X}_{\mathrm{h}}=1.22 \sqrt{\mathrm{D}_{\mathrm{e}} \mathrm{t}}
$$

Based on observations of the test failure patterns in both tests and FE models, it was found that the width of the plastic mechanism once the mechanism had fully formed $\mathrm{S}_{\mathrm{h}, \mathrm{a}}$ was, on average, $80 \%$ of the way around the quarter perimeter of the section - i.e. $\mathrm{S}_{\mathrm{h}, \mathrm{a}}=0.8 \times \mathrm{P} / 4$, where $\mathrm{P}$ is the perimeter of the ellipse. Hence, if $\mathrm{S}_{\mathrm{h}}$ is assumed to be constant, its final value should be used throughout the deformation process (Eq. 25).

$$
\mathrm{S}_{\mathrm{h}}=\mathrm{S}_{\mathrm{h}, \mathrm{a}}=0.8 \times \frac{\mathrm{P}}{4}
$$

Examining the hinge parameters based on energy minimisation (i.e. determining the values of $X_{h}$ and $S_{h}$ that minimise $N$ in Eq. 23 for a given value of $\Delta$ ) reveals that the influence of $\mathrm{X}_{\mathrm{h}}$ is very small, while the lowest energy solution is achieved when $\mathrm{S}_{\mathrm{h}}=$ $\mathrm{P} / 4$, which corresponds to the mechanism spreading around the full perimeter of the 
cross-section. However, the geometry of an EHS with an aspect ratio of two is such that, in practice, the mechanism is restricted to the flatter portions of the cross-section and does not spread into the end regions that have high local curvature and hence high stiffness. Energy minimisation is therefore achieved when the mechanism spreads to the full extent of the flatter portions of the cross-section, which corresponds to about $80 \%$ of the perimeter, as described above. The proposed mechanism parameters (based on experimental and numerical observations), therefore also match the minimum energy solution.

With $\mathrm{S}_{\mathrm{h}}$ and $\mathrm{X}_{\mathrm{h}}$ defined, Eq. 18, 22 and 23 may be employed to provide an analytical description of the load-lateral displacement response of compressed EHS failing in the split flip disc mode. Fig. 10 presents the resulting curves for $150 \times 75$ EHS with four different thicknesses, $\mathrm{t}=4,5,6.3$ and $8 \mathrm{~mm}$. These thickness values have been focussed upon since they are representative of commercially available profiles and are consistent with those previously studied experimentally. As may be seen in Fig. 10, the thicker tubes exhibit a more ductile response with a slower drop in capacity. Additionally, in Fig. 11, the load-lateral displacement curves of the analytical model for the $150 \times 75 \times 5$ and $150 \times 75 \times 8$ profiles are compared with the FE results.

However, the FE models showed that the width of the plastic mechanism, rather than being fixed, grows during plastic deformation towards its final value $\mathrm{S}_{\mathrm{h}, \mathrm{a}}$, while the height of the plastic mechanism $\mathrm{X}_{\mathrm{h}}$ remains approximately constant. Thus, defining $\mathrm{S}_{\mathrm{h}}$ as a function of the lateral displacement was investigated. Based on the FE models, $\mathrm{S}_{\mathrm{h}}$ was estimated to be the $30 \%$ of the way around the quarter perimeter of the section at the beginning of the plastic deformation, and was observed to increase more slowly in the thicker sections. Hence, it was chosen to represent $S_{h}$ with the rational expression presented in Eq. 26 that, starting at $\mathrm{S}_{\mathrm{h}}=0.3$, tends asymptotically to the value given by Eq. 25 and is controlled by the thickness t of the cross-section.

$$
\mathrm{S}_{\mathrm{h}}=\left(0.3+0.5\left(\frac{\Delta}{\Delta+3 \mathrm{t}}\right)\right) \frac{\mathrm{P}}{4}
$$

Fig. 12 shows the curves for $150 \times 75$ elliptical tubes with four different thicknesses using the $\mathrm{S}_{\mathrm{h}}$ defined in Eq. 26. Finally, Figs 13-16 present a comparison between the analytical model and the FE results with this $S_{h}$ value. The accuracy of the analytical 
model with the different $\mathrm{X}_{\mathrm{h}}$ and $\mathrm{S}_{\mathrm{h}}$ parameters defined above is discussed in Section 7.

\section{Construction of the load-end shortening curves}

The load-lateral displacement curves presented in the previous section can be readily transformed into load-end shortening $(\mathrm{N}-\delta)$ curves with reference to Fig. 8 through Eq. 27.

$\delta=2\left(\mathrm{X}_{\mathrm{h}}-\sqrt{\mathrm{X}_{\mathrm{h}}^{2}-\Delta^{2}}\right)$

However, particularly for stocky sections, considerable end shortening may take place prior to the formation and subsequent development of the plastic collapse mechanism. Therefore, in order to construct the full load-end shortening curve, axial deformation associated with the elastic, yield plateau and strain hardening stages of the material stress-strain response should also be incorporated. Progression through these stages of deformation will depend on the deformation capacity of the cross-section, which, in turn, is linked to the slenderness of the cross-section.

The slenderness of an elliptical hollow section $\lambda_{\text {EHS }}$ may be defined by Eq. 28 [25].

$\lambda_{\text {EHS }}=\frac{f_{y} \sqrt{3\left(1-v^{2}\right)}}{E} \frac{D_{e}}{2 t}$

in which $v$ is Poisson's modulus and E is Young's modulus.

The deformation capacity of elliptical sections may be determined on the basis of their maximum axial deformation $\delta_{\max }$ prior to a drop in load-carrying capacity. Fig. 17 shows the FE and test deformation capacity, presented in a normalised form as $\varepsilon_{\mathrm{LB}} / \varepsilon_{\mathrm{y}}$, where $\varepsilon_{\mathrm{LB}}=\delta_{\mathrm{max}} / \mathrm{L}, \mathrm{L}$ being the stub column length, and $\varepsilon_{\mathrm{y}}=\mathrm{f}_{\mathrm{y}} / \mathrm{E}$ is the yield strain of the section, plotted against cross-section slenderness $\lambda_{\text {EHS. The predictive }}$ expression given by Eq. 29, in which the coefficients have been adjusted by regression to fit the FE and test results, has also been added to Fig. 17, and is of the same form as that employed to predict the deformation capacity of steel cross-sections comprising flat elements [33]. 


$$
\frac{\varepsilon_{\mathrm{LB}}}{\varepsilon_{\mathrm{y}}}=\frac{0.037}{\lambda_{\text {EHS }}^{2.4}}
$$

The analytical model developed in Section 5 assumes rigid plastic material behaviour. However, following a yield plateau, the actual stress-strain response of hot-finished steel also exhibits strain hardening. The three stages of the material stress-strain response of hot-finished EHS can be approximated by a tri-linear model, as shown in Fig. 18. The slope of the elastic stage is given by the Young's modulus of the material, while the strain at the onset of strain hardening $\varepsilon_{\text {sh }}$ and the slope of the strain hardening regime $\mathrm{E}_{\mathrm{sh}}$ were defined based on mean values from the available test data on hot-finished [2]: $\varepsilon_{\mathrm{sh}}=0.02$ and $\mathrm{E}_{\mathrm{sh}}=\mathrm{E} / 100$.

The unloading branch of the load-end shortening curve may be obtained from the analytical model derived in Section 5 on the basis of $f_{y}$ for sections with deformation capacities below the onset of strain hardening. For sections that progress into the strain hardening regime, $f_{y}$ in the analytical model is replaced by $f_{L B}$, which is the stress corresponding to $\varepsilon_{\mathrm{LB}}$ and is given by:

$\mathrm{f}_{\mathrm{LB}}=\mathrm{f}_{\mathrm{y}}+\mathrm{E}_{\mathrm{sh}}\left(\varepsilon_{\mathrm{LB}}-\varepsilon_{\mathrm{sh}}\right) \quad$ for $\varepsilon_{\mathrm{LB}}>\varepsilon_{\mathrm{sh}}$

Hence, once Eq. 27 has been used to transform the lateral deformation into end shortening, the full load-end shortening curve may be obtained with $\varepsilon_{\text {LB }}$ which is a function of cross-section slenderness, defining the longitudinal strain that the crosssection can sustain prior to unloading. Fig. 19 presents the analytical load-end shortening curves for $150 \times 75$ elliptical profiles of different thickness. Figs 20-23 show comparisons between the analytical model and corresponding tests results.

\section{Comparison between analytical model and observed behaviour}

The analytical model developed in Sections 5 and 6 are assessed in this section by reference to the results from the FE study and the tests presented in [2]. The comparisons presented in Figs 13-16 and 20-23 are discussed. During the experimental work [2], load and end shortening data were recorded, but lateral displacement was not since it is not possible to predict where exactly the plastic hinge is going to develop. Hence, the load-lateral displacement results from the analytical 
model have been compared with FE results, while the load-end shortening results from the analytical model have been compared with the experimental data.

The analytical load-lateral displacement curves, determined using the parameters $\mathrm{X}_{\mathrm{h}}$ and $\mathrm{S}_{\mathrm{h}}$ defined by Eqs. 24 and 26 respectively, are compared with the FE results in Figs 13-16. The analytical model may be seen to closely follow the shape of the unloading curves obtained from the FE models, for the studied range of EHS. More specifically, for the $150 \times 75 \times 4$ EHS (Fig. 13) the maximum disparity between analytical and $\mathrm{FE}$ results was $7 \%$ at $\Delta=30 \mathrm{~mm}$. For the remaining three section sizes, the maximum disparities were less, being $3.9 \%$ at $\Delta=10 \mathrm{~mm}$ for the $150 \times 75 \times 5$ EHS (Fig. 14), 2.5\% over the majority of the deformation range for the $150 \times 75 \times 6.3 \mathrm{EHS}$ (Fig. 15), and $3.7 \%$ in the early stages of deformation for the $150 \times 75 \times 8$ EHS (Fig. 16).

Figs 20-23 show comparisons between the analytical load-end shortening curves and the tests results. Overall, it may be observed that the full experimental load-end shortening histories can be well predicted from the developed analytical model, including the elastic, yield plateau, strain hardening and unloading regimes.

\section{Conclusions}

Local plastic collapse mechanisms in compressed EHS have been examined in this paper. From an initial parametric study, four possible collapse mechanisms were identified, two of which were akin to plate-like behaviour and two to shell-like behaviour. A numerical study, coupled with examination of existing test data, revealed that the so-called split flip disc mechanism arose most frequently. Hence, an analytical model to describe the compressive load-lateral displacement response of EHS failing by this mechanism was derived herein. The analytical model was developed by applying rigid plastic theory to a postulated plastic collapse mechanism for elliptical sections. Simple expressions, posed in terms of section geometry, to determine the key parameters required to fully describe the shape of the plastic hinges were establish. Following this, a relationship between lateral displacement and end shortening was derived, which, coupled with a deformation based method and a trilinear material model, enabled the full load-end shortening history of compressed EHS to be established. 
Comparisons between the analytical model and both FE and experimental data revealed good agreement over a range of cross-section slenderness. The maximum discrepancy in the load-lateral displacement curves was the $7 \%$, while the load-end shortening curves followed the experimental curves adequately. Hence, it may be concluded that the derived analytical model provides an accurate means of predicting the load-displacement response of a compressed EHS undergoing local plastic collapse in the split flip disc mechanism.

\section{Acknowledgements}

The authors would like to thank Carlos Arévalo-Robles for his contribution to this work and would like to acknowledge the Basque Government (Department of Education, Universities and Research) for the financial support given under the overseas post-doctoral development scheme in 2009 and 2010.

\section{References}

[1] Murray NW. Introduction to the theory of thin-walled structures. Oxford University Press 1984.

[2] Chan TM, Gardner L. Compressive resistance of hot-rolled elliptical hollow sections. Engineering Structures 2008;30(2),522-532.

[3] Ruiz-Teran AM, Gardner L. Elastic buckling of elliptical tubes. Thin-Walled Structures 2008;46(11):1304-1318.

[4] Silvestre N, Gardner L. Elastic local post-buckling of elliptical tubes. Journal of Constructional Steel Research (submitted).

[5] Mahendran M. Local plastic mechanisms in thin steel plates under in-plane compression. Thin-Walled Structures 1997;27(3):254-261.

[6] Meng Q, Al-Hassani STS, Soden PD. Axial crushing of square tubes. International Journal of Mechanics and Science 1983;25(9):747-773. 
[7] Zhao XL, Van Binh D, Al-Mahaidi R, Tao Z. Stub column tests of fabricated square and triangular sections utilizing very high strength steel tubes. Journal of Constructional Steel Research 2004;60(11): 1637-1661.

[8] Ye JH, Zhao XL, Van Binh D, Al-Mahaidi R. Plastic mechanism analysis of fabricated square and triangular sections under axial compression. Thin-Walled Structures 2007;45(2):135-148.

[9] Li S, Reid SR. Relationship between the elastic buckling of square tubes and rectangular plates. Journal of Applied Mechanics 1990;57(4):969-973.

[10] Andrews KRF, England GL, Ghani E. Classification of the axial collapse of cylindrical tubes under quasi-static loading. International Journal of Mechanics and Science 1983;25(9):687-696.

[11] Guillow SR, Lu G, Grzebieta RH. Quasi-static axial compression of thin-walled circular aluminium tubes. International Journal of Mechanical Sciences 2001;43(9):2103-2123.

[12] Grzebieta RH. An alternative method for determining the behaviour of round stocky tubes subjected to an axial crush load. Thin-Walled Structures 1990;9(1-4):6189.

[13] Gupta NK, Velmurugan R. An analysis of axi-symmetric axial collapse of round tubes. Thin-Walled Structures 1995;22(4):261-274.

[14] Johnson W, Soden PD, Al-Hassani STS. Inextensional collapse of thin-walled tubes under axial compression. Journal of Strain Analysis 1977;12(4):317-330.

[15] Almkvist G, Berndt B. Gauss, Landen, Ramanujan. The arithmetic-geometric mean, ellipses, $\pi$, and the ladies diary. The American Mathematical Monthly 1988;95(7):585-608.

[16] Marguerre K. Stability of the cylindrical shell of variable curvature. Technical memorandum 1302, National Advisory Committee for Aeronautics, Washington, 1951. 
[17] Kempner J. Some results on buckling and postbuckling of cylindrical shells. Collected papers on instability of shell structures. NASA TND-1510, December 1962:173-186. NASA Polytechnic Institute of Brooklyn.

[18] Hutchinson JW. Buckling and initial post-buckling behaviour of oval cylindrical shell under axial compression. Journal of Applied Mechanics 1968;24:66-72.

[19] Kempner J, Chen YN. Large deflections of an axially compressed oval cylindrical shell. $11^{\text {th }}$ international congress of applied mechanics, MunichBerlin:Springer;1964:299-305.

[20] Kempner J, Chen YN. Buckling and post-buckling of an axially compressed oval cylindrical shell. $17^{\text {th }}$ anniversary symposium on shells to honour Lloyd Hamilton Donnell, 1966. Houston, TX.

[21] Kempner J, Chen YN. Post-buckling of an axially compressed oval cylindrical shell. $12^{\text {th }}$ international congress of applied mechanics. Standford University, 1968:246-256.

[22] Tennyson RC, Booton M, Caswell RD. Buckling of imperfect elliptical cylindrical shells under axial compression. American Inst Aeronautics Astronautics Journal 1971;9(2):250-255.

[23] Zhao XL, Packer JA. Tests and design of concrete-filled elliptical hollow section stub columns. Thin-Walled Structures 2009;47(6-7):617-628.

[24] Chan TM, Gardner L. Bending strength of hot-rolled elliptical hollow sections. Journal of Constructional Steel Research 2008;64(9):971-986.

[25] Gardner L, Chan TM. Cross-section classification of elliptical hollow sections. Steel and Composites Structures 2007;7(3):185-200.

[26] Silvestre N. Buckling behaviour of elliptical cylindrical shells and tubes under compression. International Journal of Solids and Structures 2008;45(16):4427-4447.

[27] Chan TM, Gardner L. Flexural buckling of elliptical hollow section columns. Journal of Structural Engineering-ASCE 2009;135(5):546-557. 
[28] Yang H, Lam D, Gardner L. Testing and analysis of concrete-filled elliptical hollow sections. Engineering Structures 2008;30(12):3771-3781.

[29] Dai X, Lam D. Numerical modelling of the axial compressive behaviour of short concrete-filled elliptical steel columns. Journal of Constructional Steel Research 2010;66(7):931-942.

[30] Willibald S, Packer JA, Martinez-Saucedo G. Behaviour of gusset plate connections to ends of round and elliptical hollow structural section members. Canadian Journal of Civil Engineering 2006;33(4):373-383.

[31] Martinez-Saucedo G, Packer JA, Zhao XL. Static design of elliptical hollow section end-connections. Proceedings of the Institution of Civil Engineers - Structures and Buildings 2008;161(2):103-113.

[32] ABAQUS. ABAQUS/Standard user's manual volumes I-III and ABAQUS CAE manual. Version 6.6. (Pawtucket, USA): Hibbitt, Karlsson and Sorensen, Inc; 2006.

[33] Gardner L, Wang F. Influence of strain hardening on the behaviour and design of steel structures. International Journal of Structural Stability and Dynamics (submitted). 


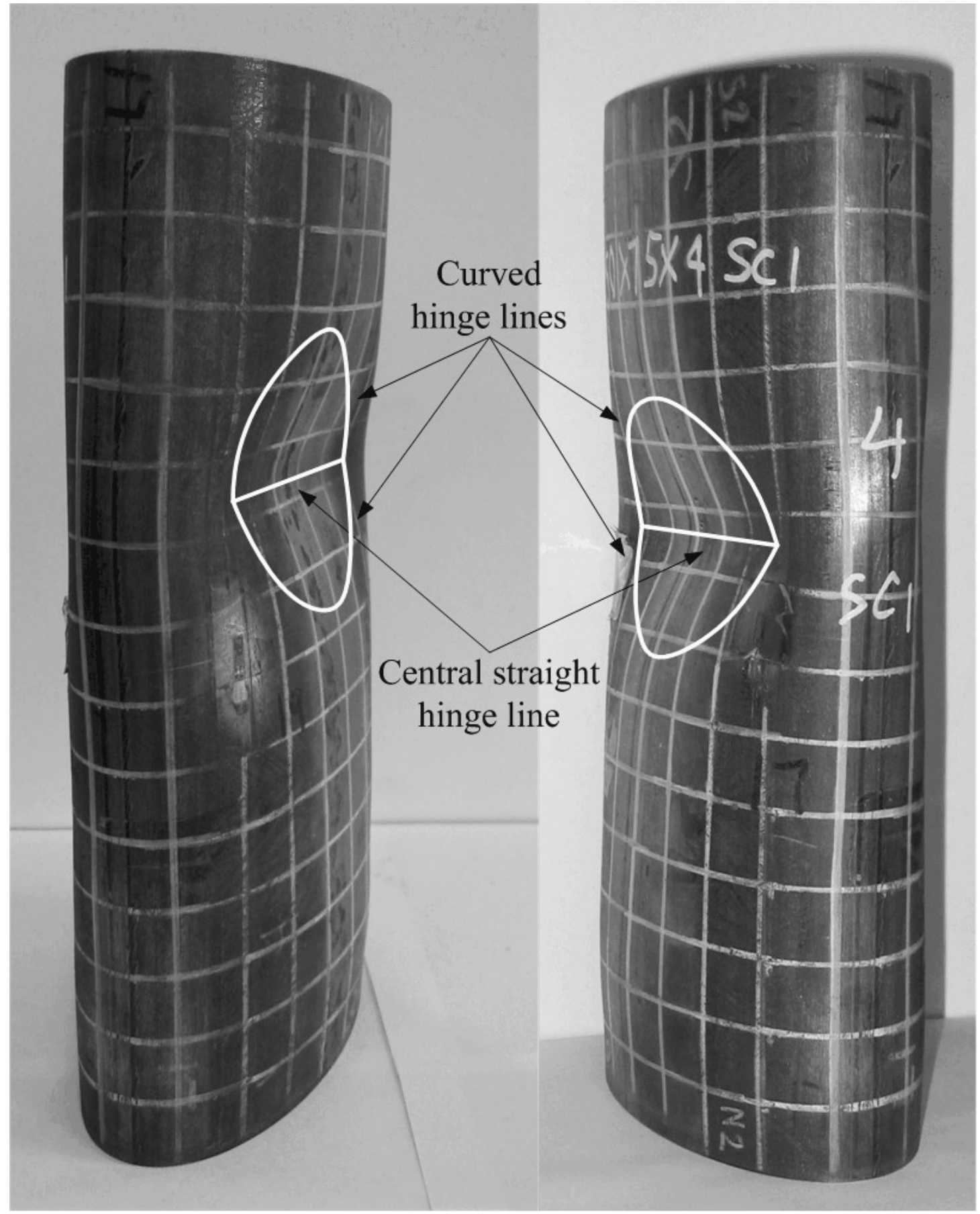

Figure 1. Split flip disc mechanism observed in two different $150 \times 75 \mathrm{~mm}$ tests. 


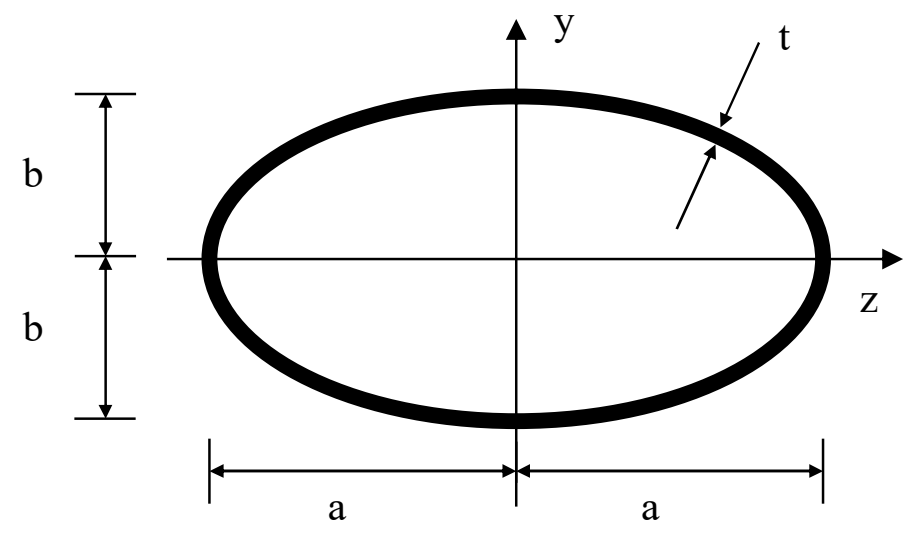

Figure 2. Geometry of an elliptical hollow section. 

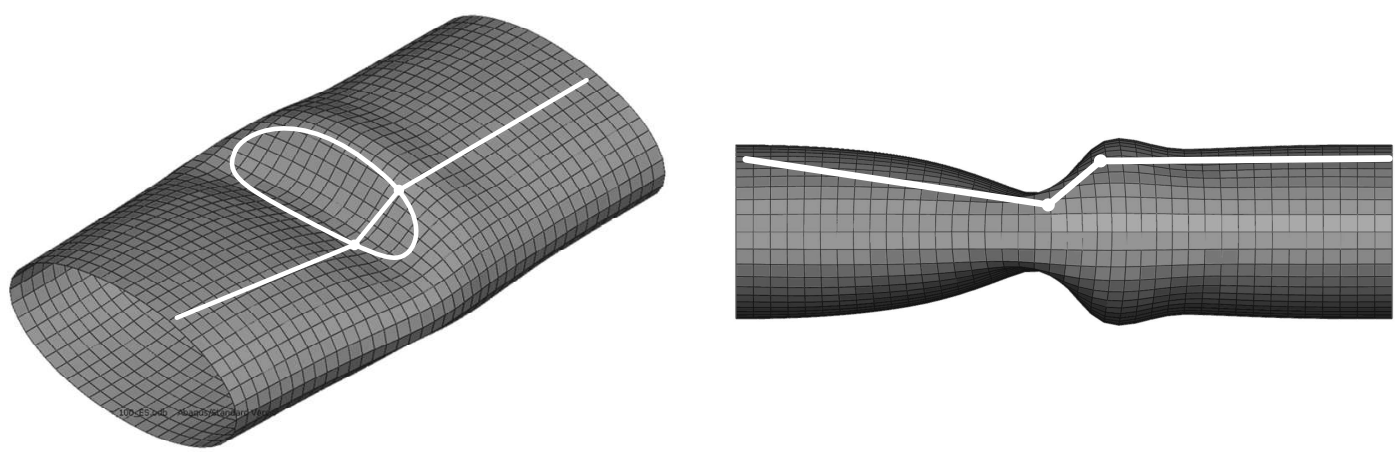

(a) Flip disc mechanism (FD)
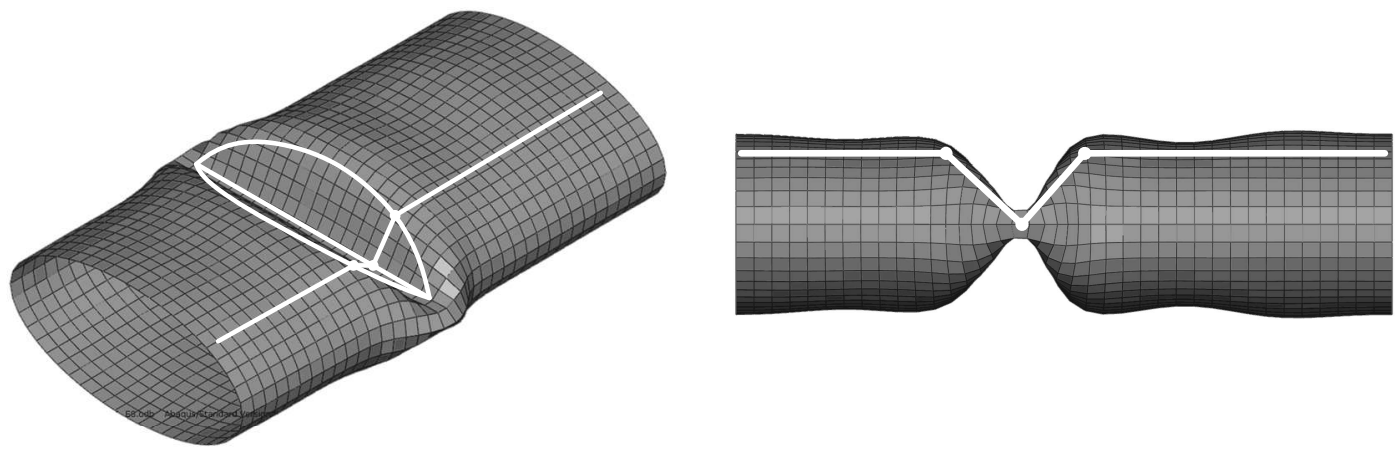

(b) Split flip disc mechanism (SFD)
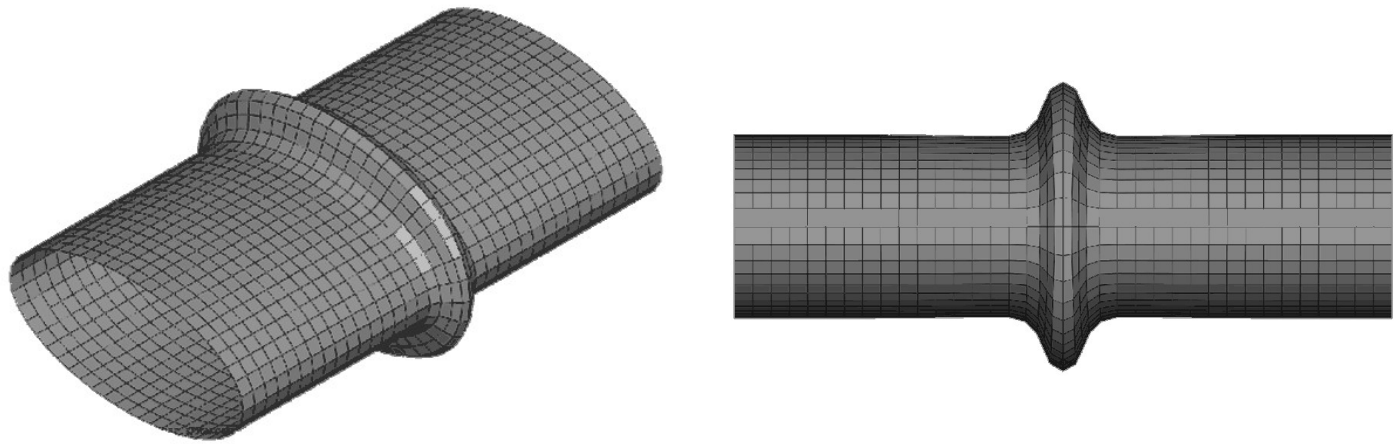

(c) Elephant foot mechanism (EF)
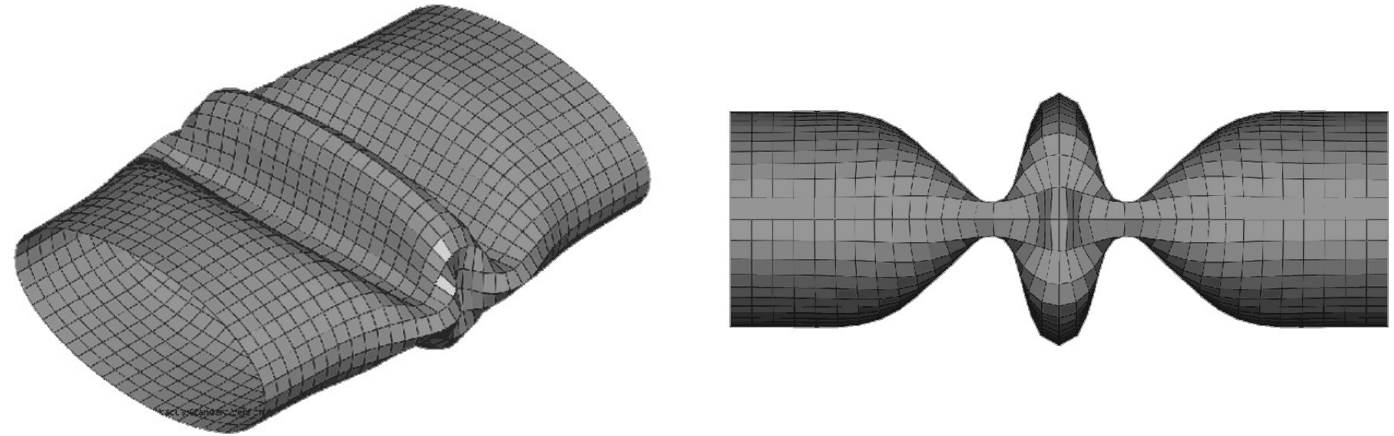

(d) Yoshimura mechanism (Y)

Figure 3. Plastic collapse mechanisms obtained from FE models for EHS. 


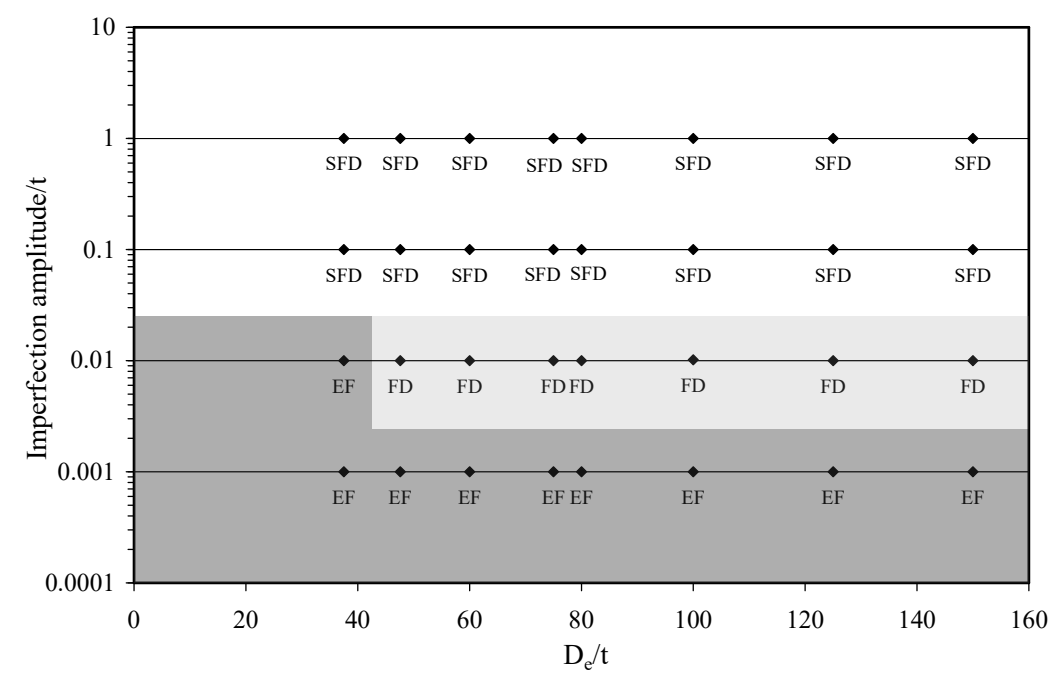

(a) Symmetrical positive

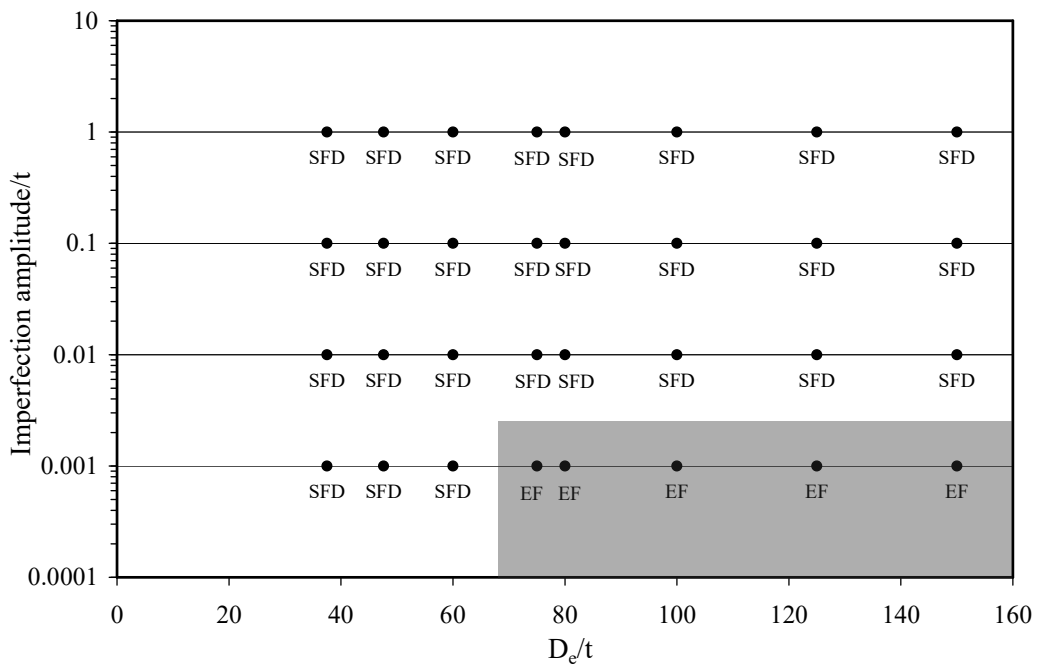

(b) Symmetrical negative

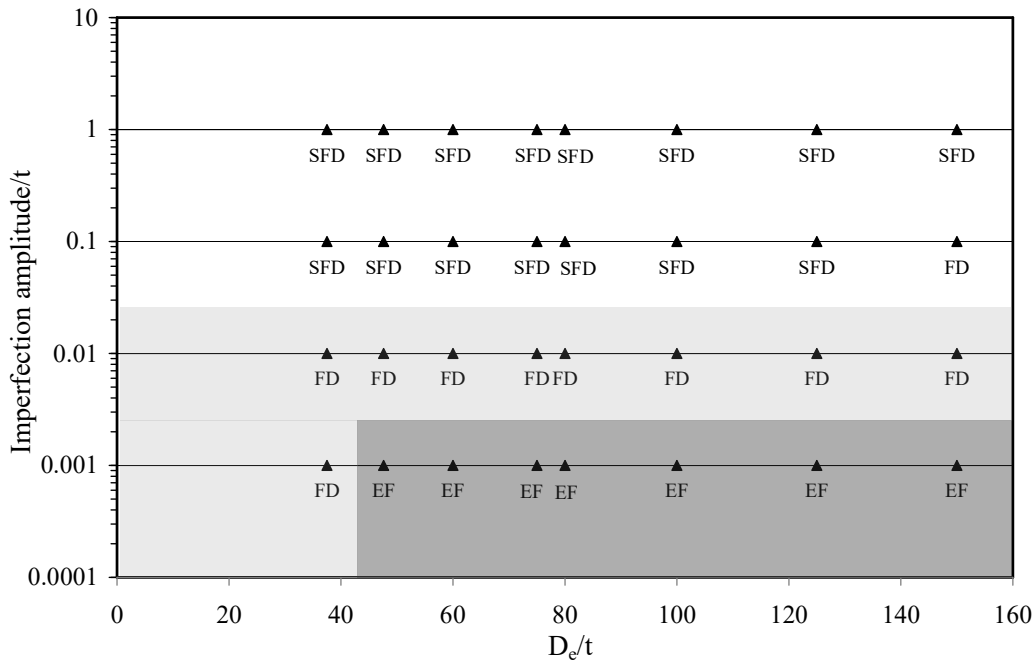

(c) Asymmetrical

Figure 4. Plastic collapse mechanisms in EHS obtained from FE models for varying cross-section slenderness and initial imperfection. 

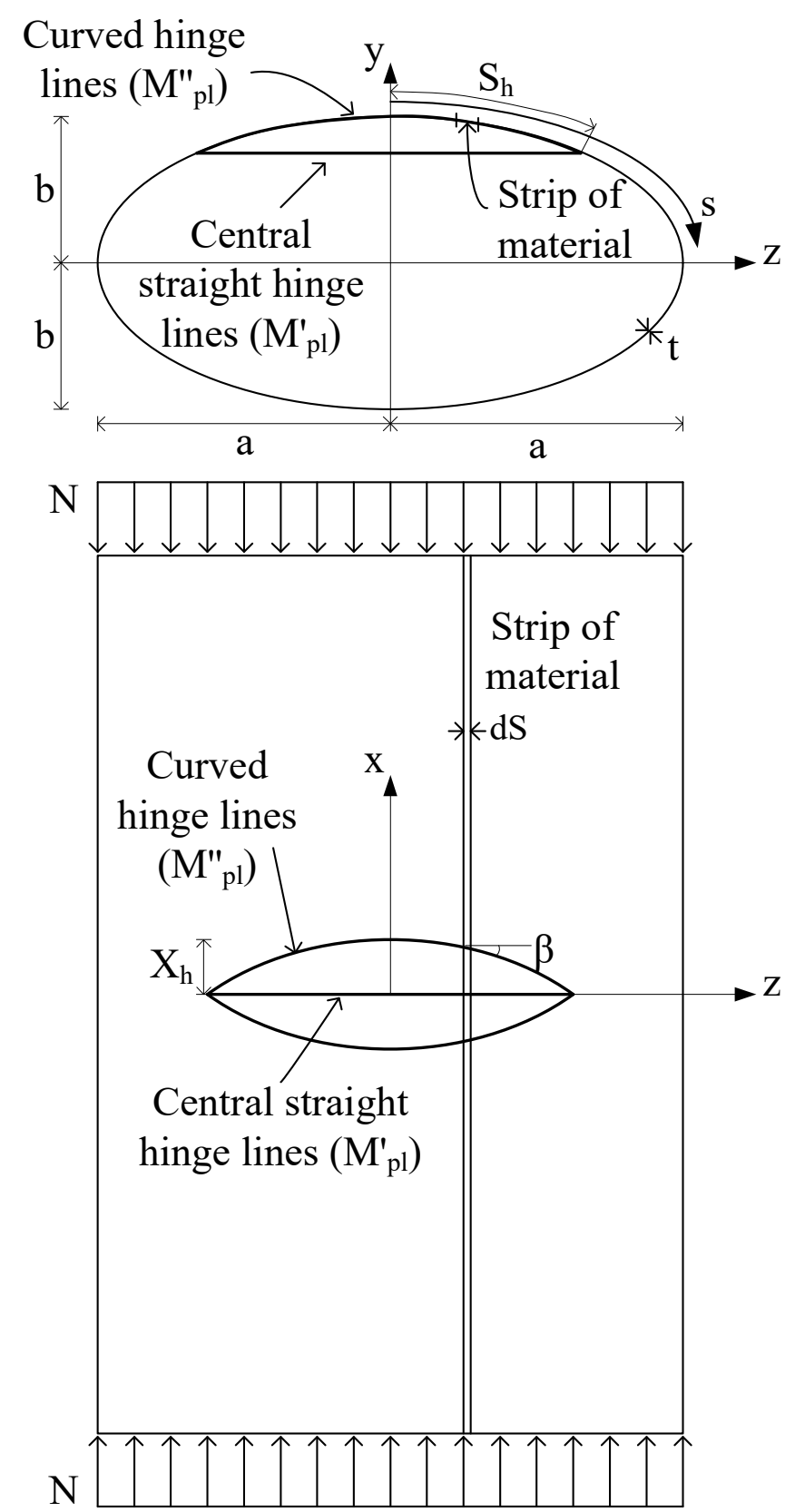

Figure 5. Shape of plastic mechanism and definition of notation. 

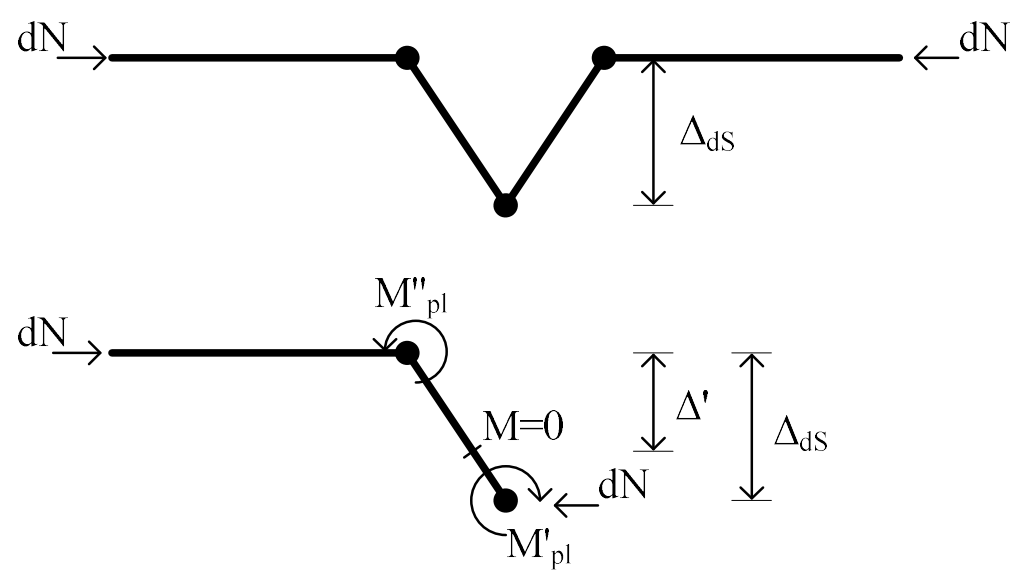

Figure 6. Free body diagram of the material strip.

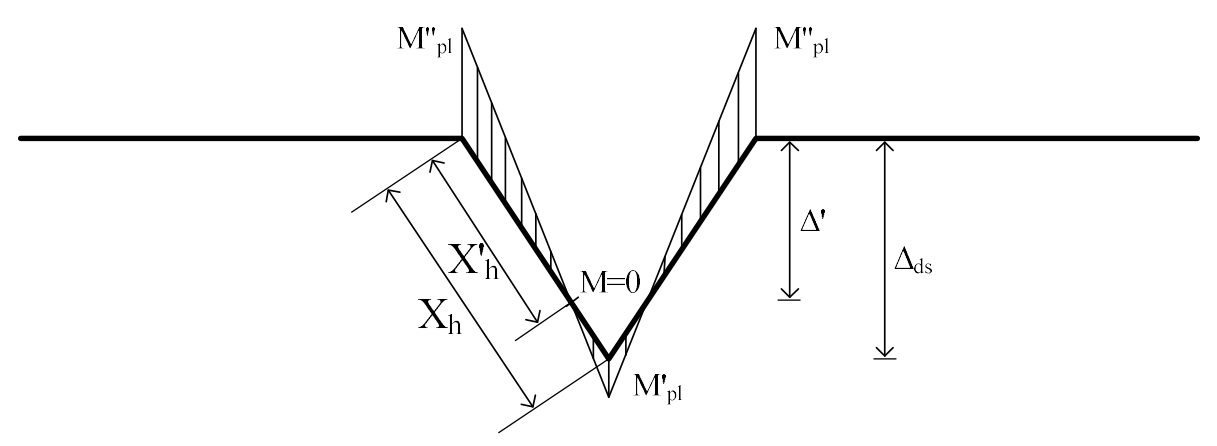

Figure 7. Bending moment diagram of the material strip.

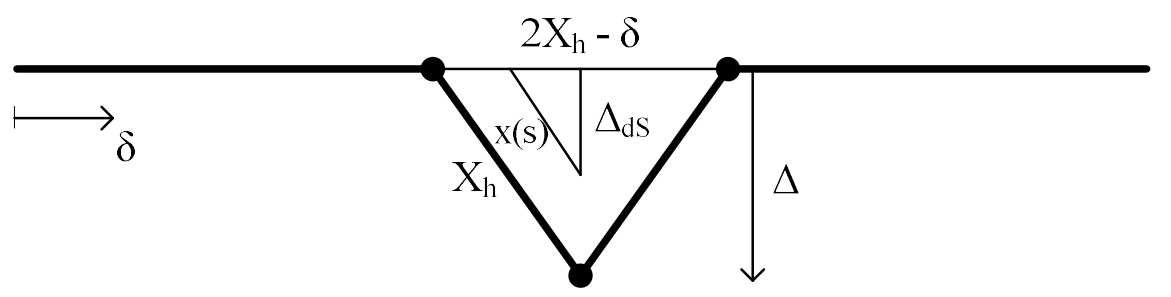

Figure 8. Relationship between lateral deformation $\Delta$ and end shortening $\delta$. 


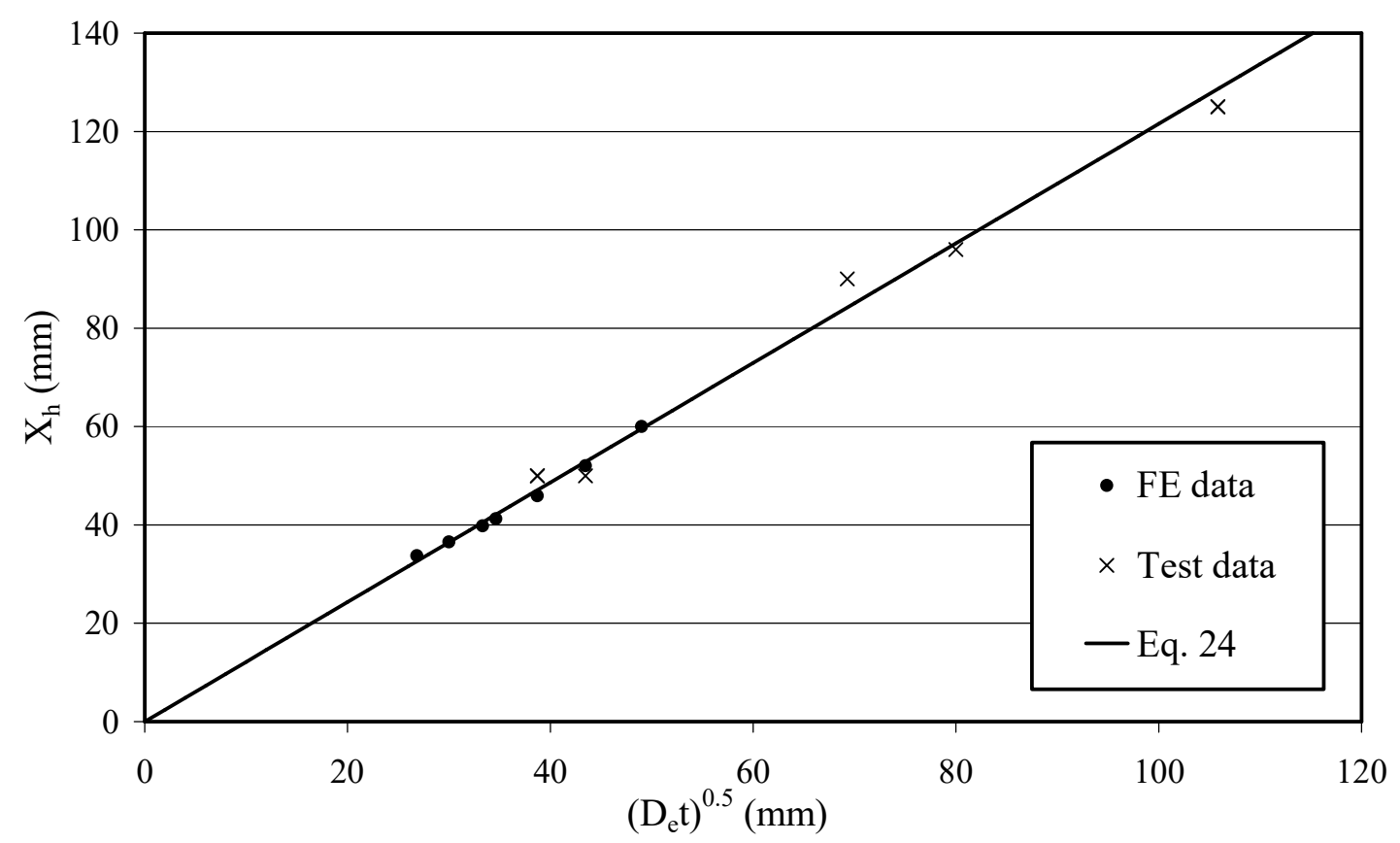

Figure 9. $\mathrm{X}_{\mathrm{h}}$ values from the FE models and the tests.

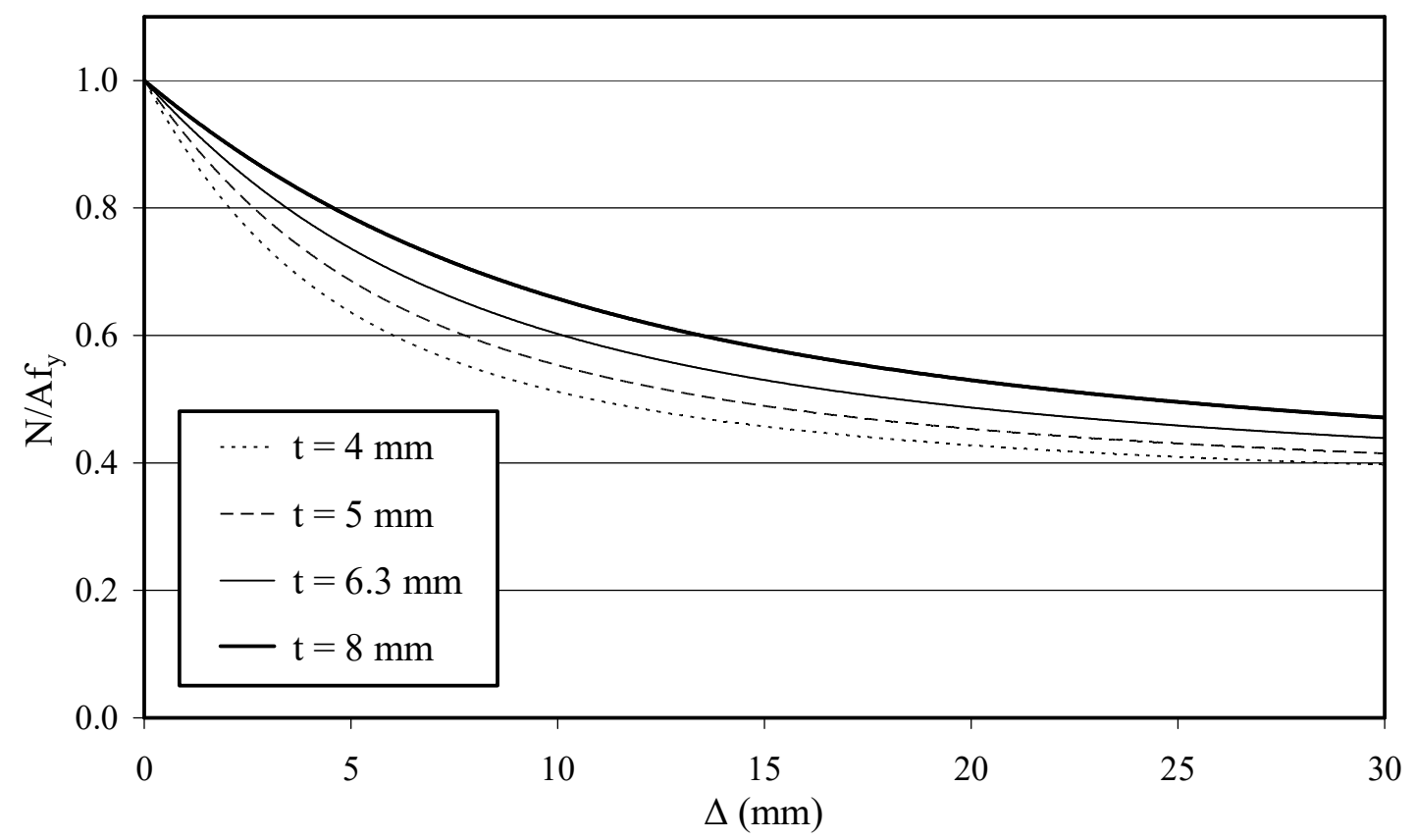

Figure 10. Analytical load-lateral displacement curves for $150 \times 75$ EHS of different thickness with $\mathrm{S}_{\mathrm{h}}=0.8 \times \mathrm{P} / 4$. 


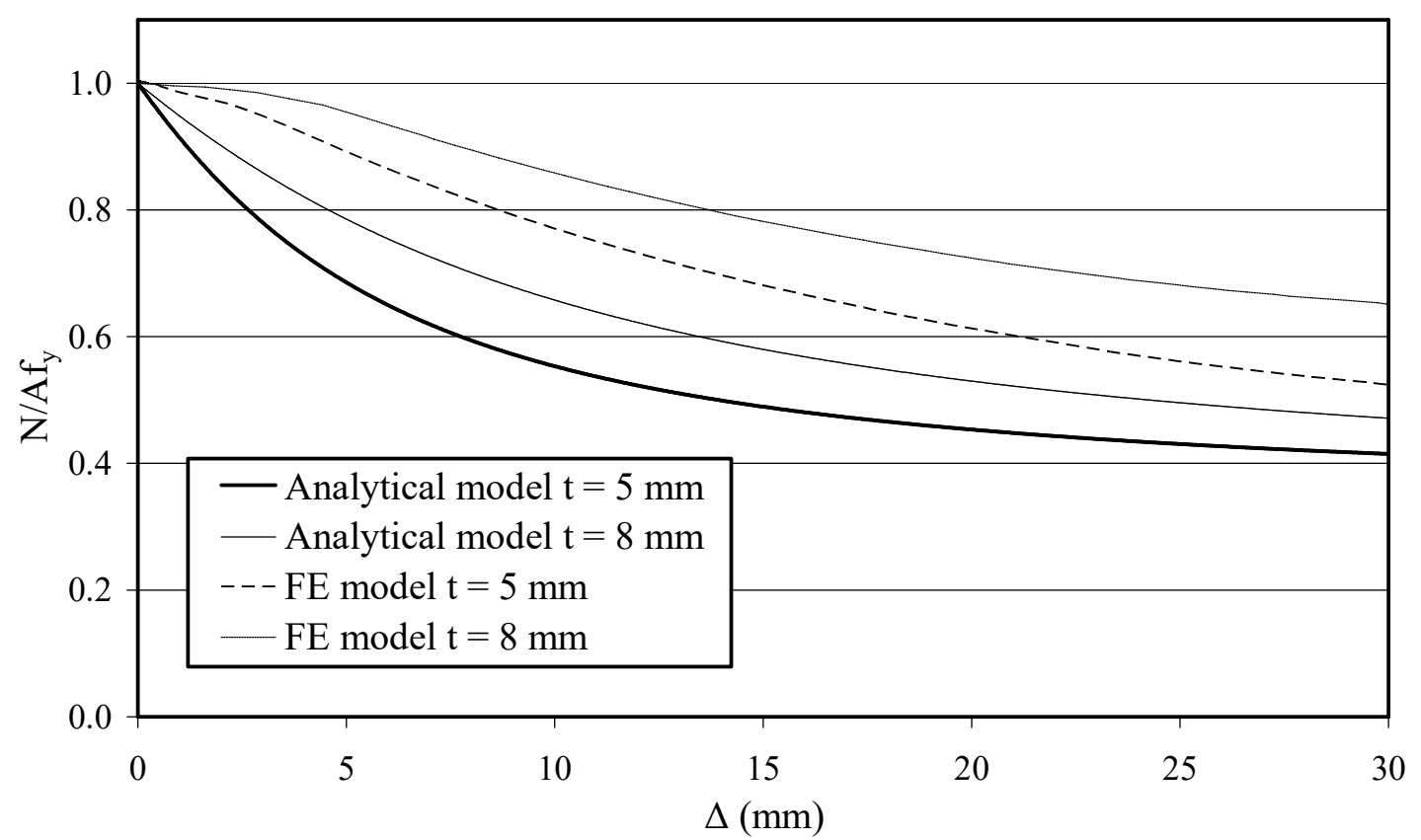

Figure 11. Comparison of load-lateral displacement responses of $150 \times 75$ EHS from the analytical model with $\mathrm{S}_{\mathrm{h}}=0.8 \times \mathrm{P} / 4$ and the FE models.

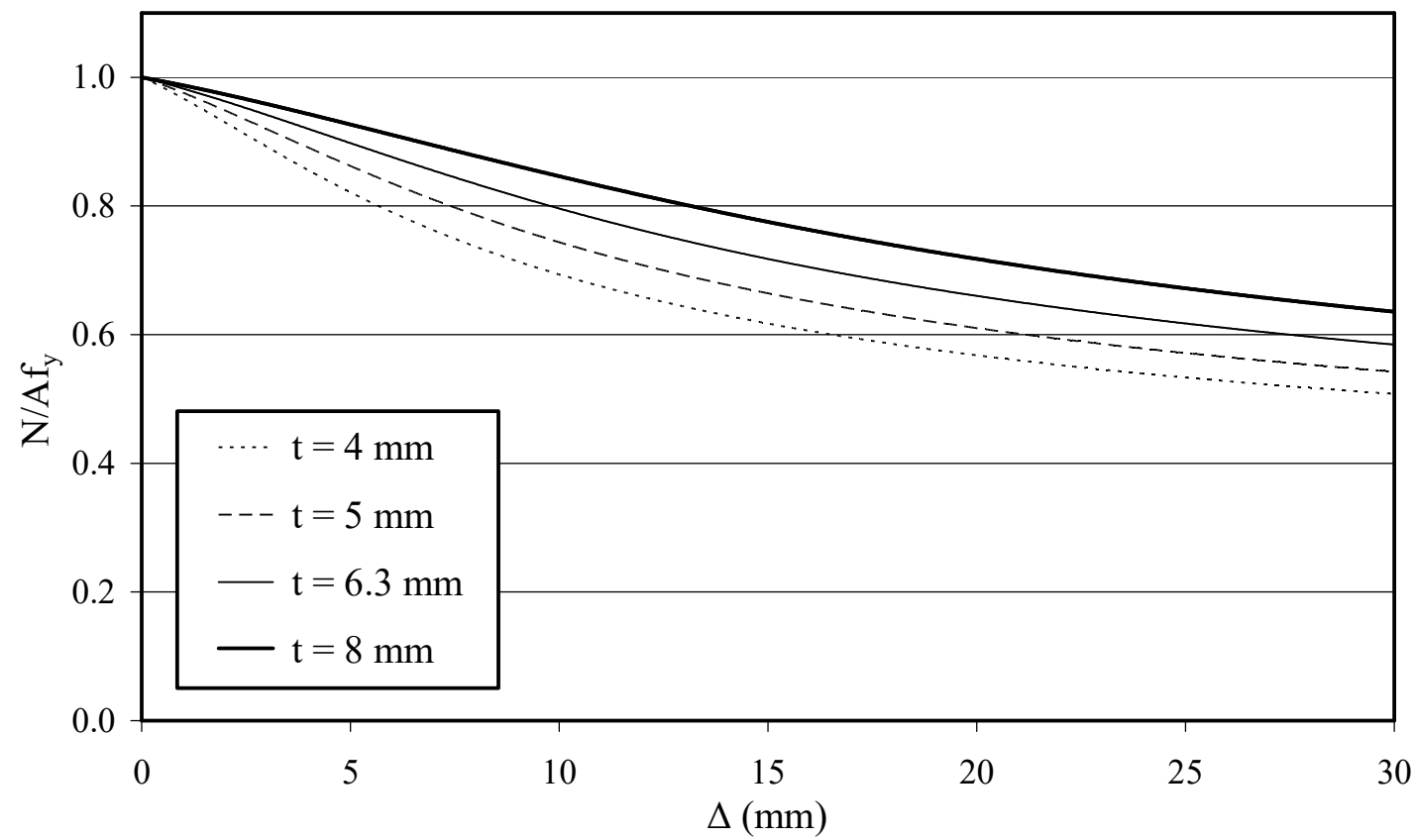

Figure 12. Analytical load-lateral displacement curves for $150 \times 75$ EHS of different thickness with $\mathrm{S}_{\mathrm{h}}(\Delta)$. 


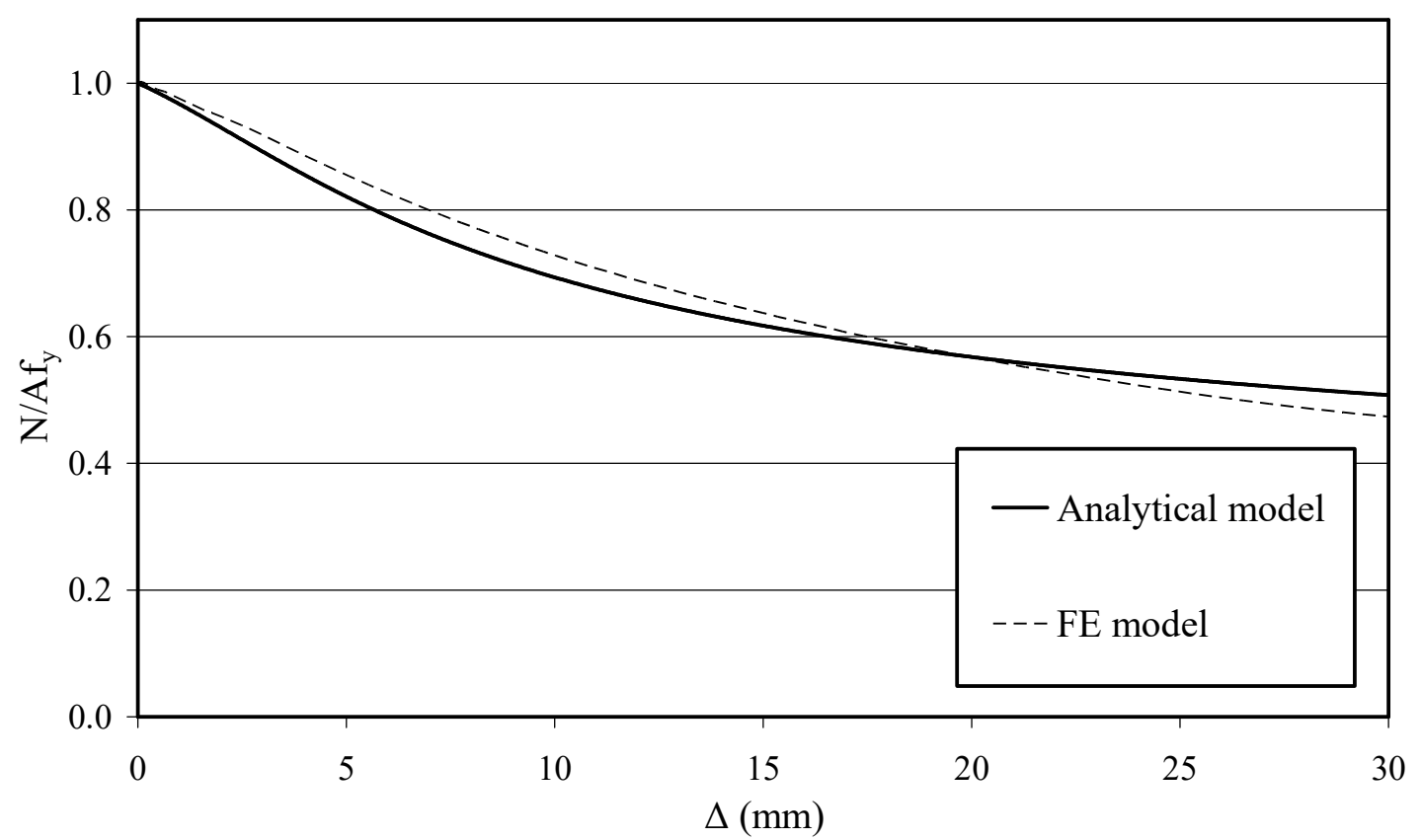

Figure 13. Comparison of load-lateral displacement responses of $150 \times 75 \times 4$ EHS from the analytical model with $\mathrm{S}_{\mathrm{h}}(\Delta)$ and the FE model.

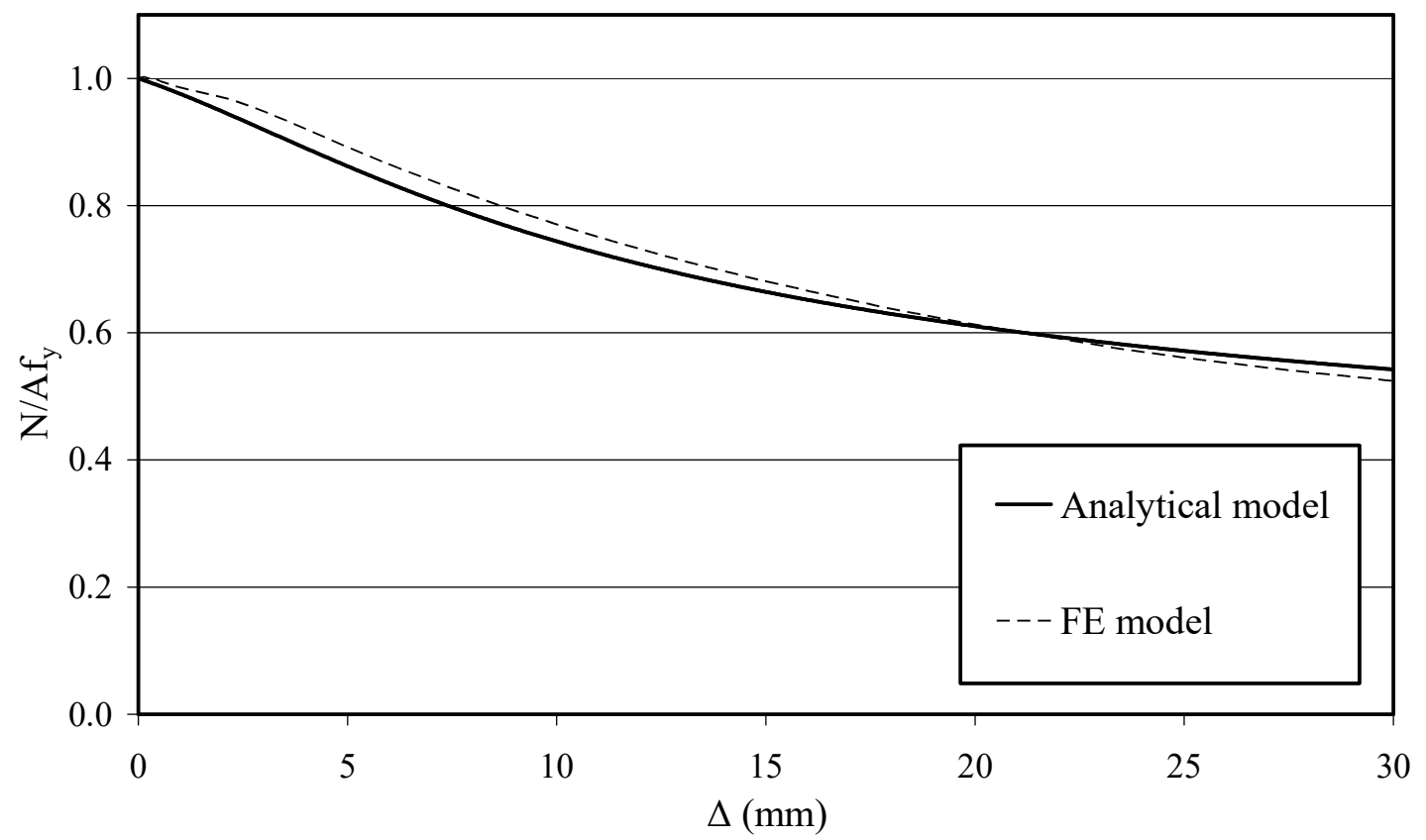

Figure 14. Comparison of load-lateral displacement responses of $150 \times 75 \times 5$ EHS from the analytical model with $\mathrm{S}_{\mathrm{h}}(\Delta)$ and the FE model. 


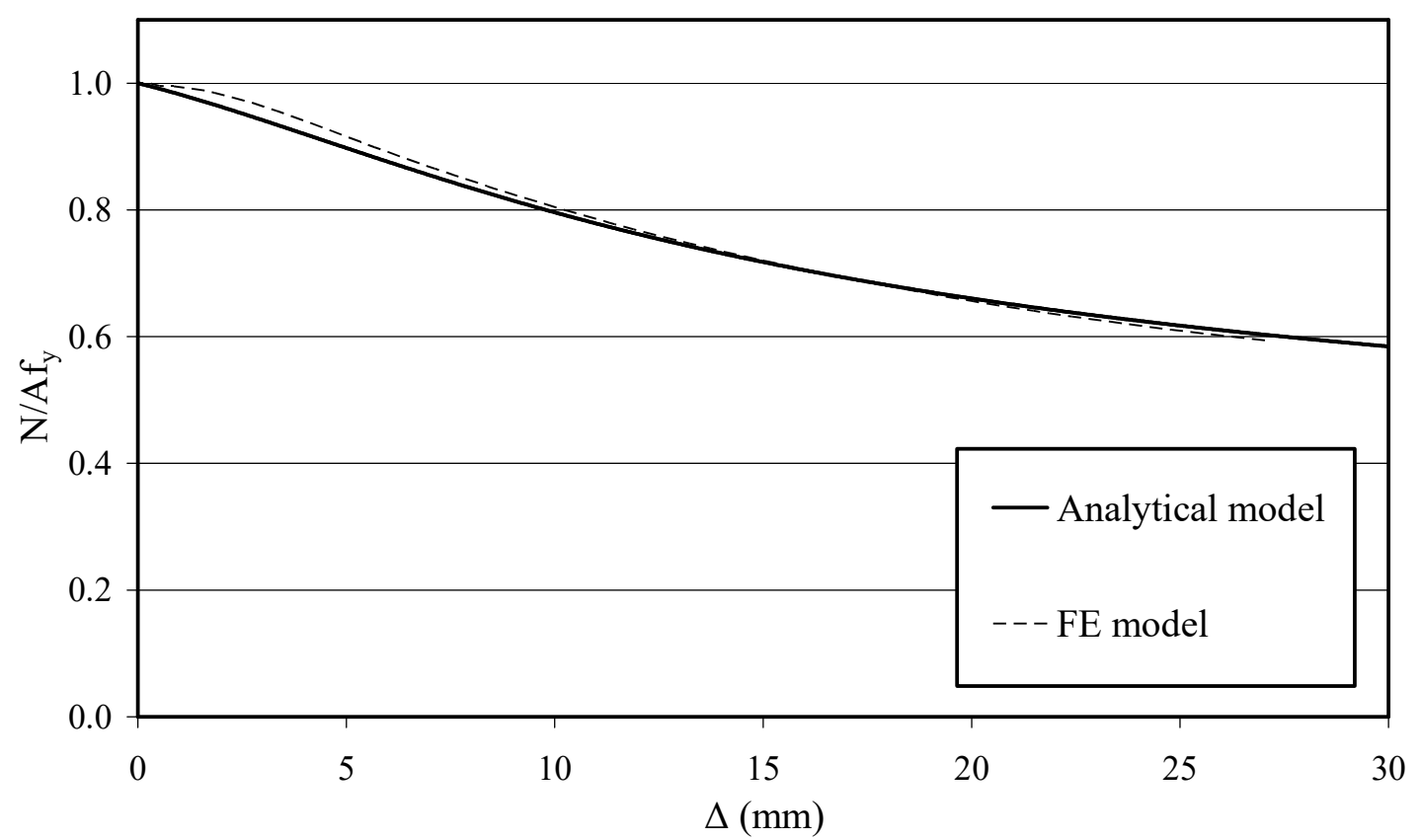

Figure 15. Comparison of load-lateral displacement responses of $150 \times 75 \times 6.3$ EHS from the analytical model with $\mathrm{S}_{\mathrm{h}}(\Delta)$ and the FE model.

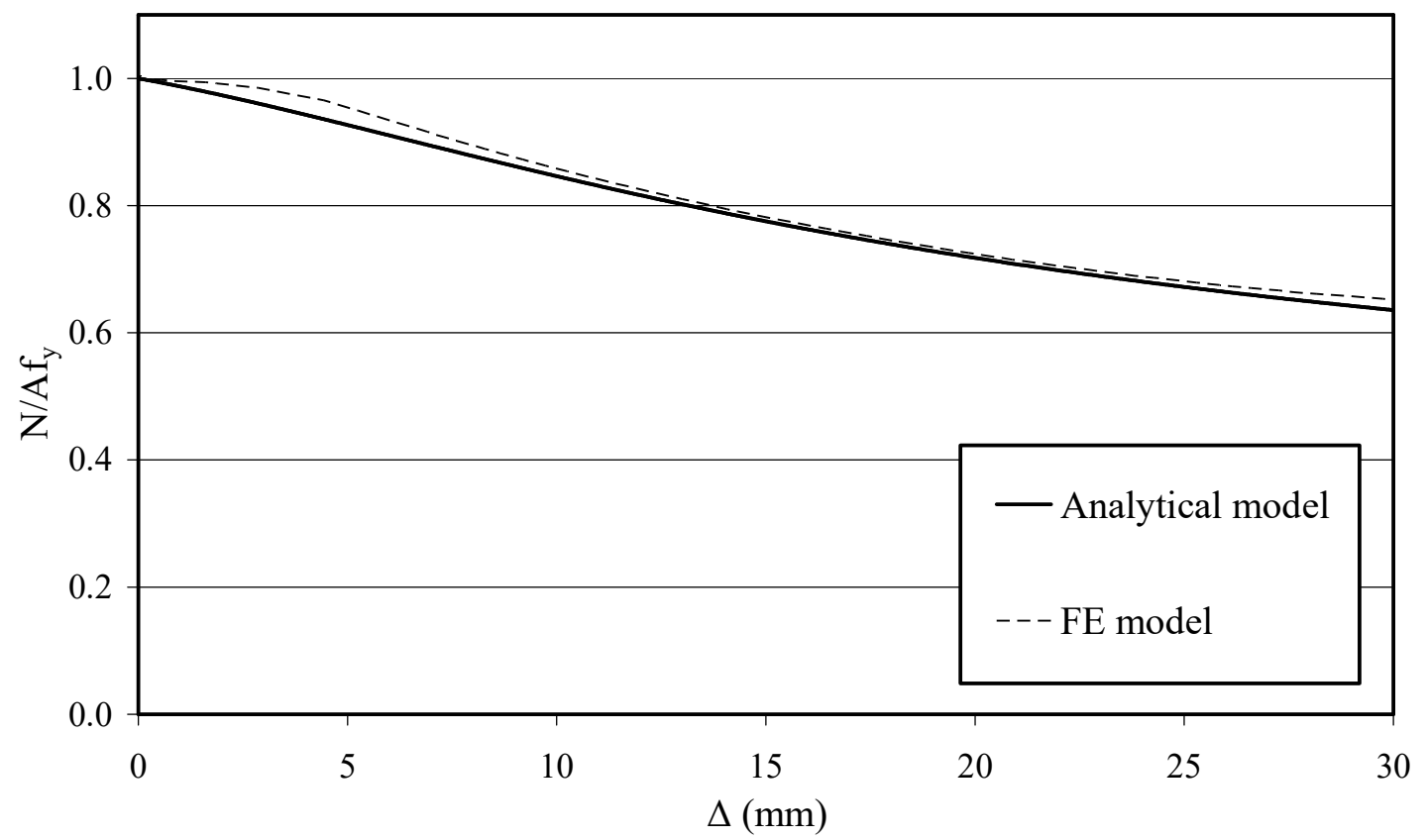

Figure 16. Comparison of load-lateral displacement responses of $150 \times 75 \times 8$ EHS from the analytical model with $\mathrm{S}_{\mathrm{h}}(\Delta)$ and the FE model. 


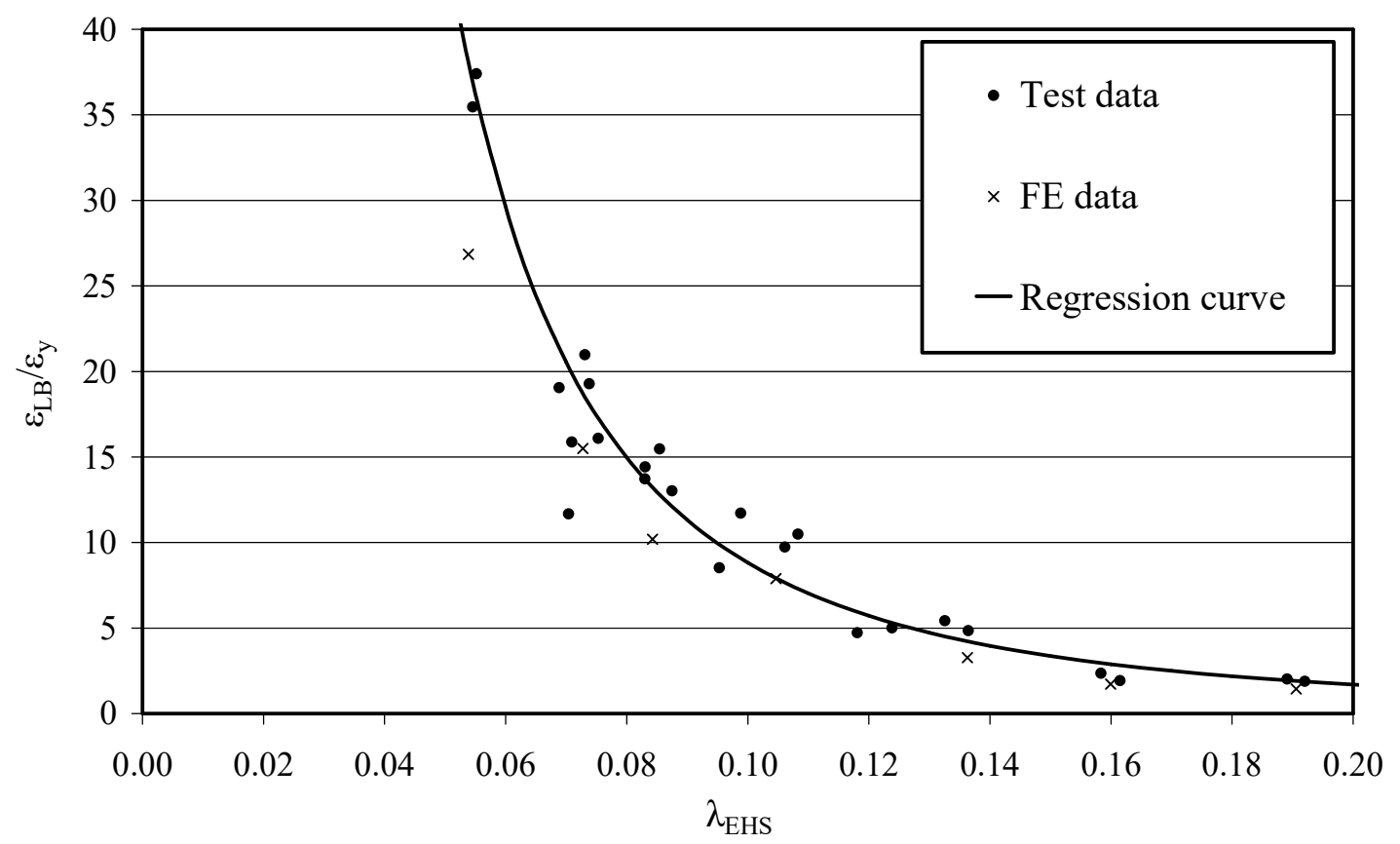

Figure 17. Relationship between deformation capacity and slenderness for EHS.

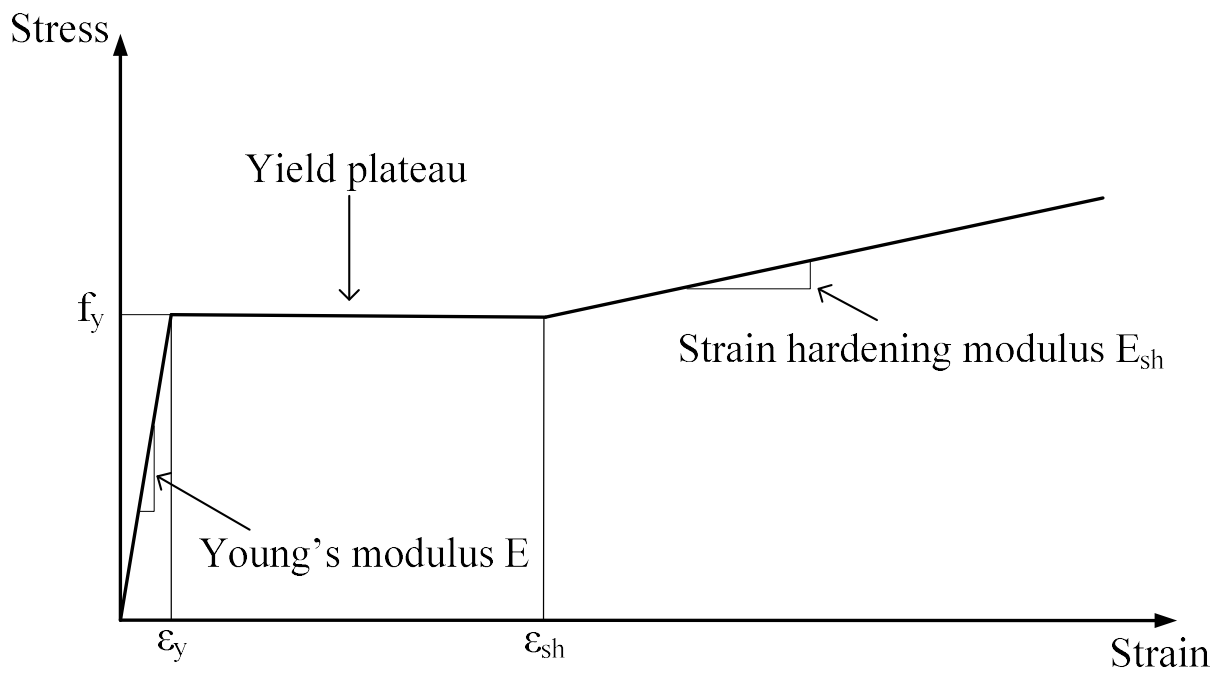

Figure 18. Stress-strain curve of hot-finished steel. 


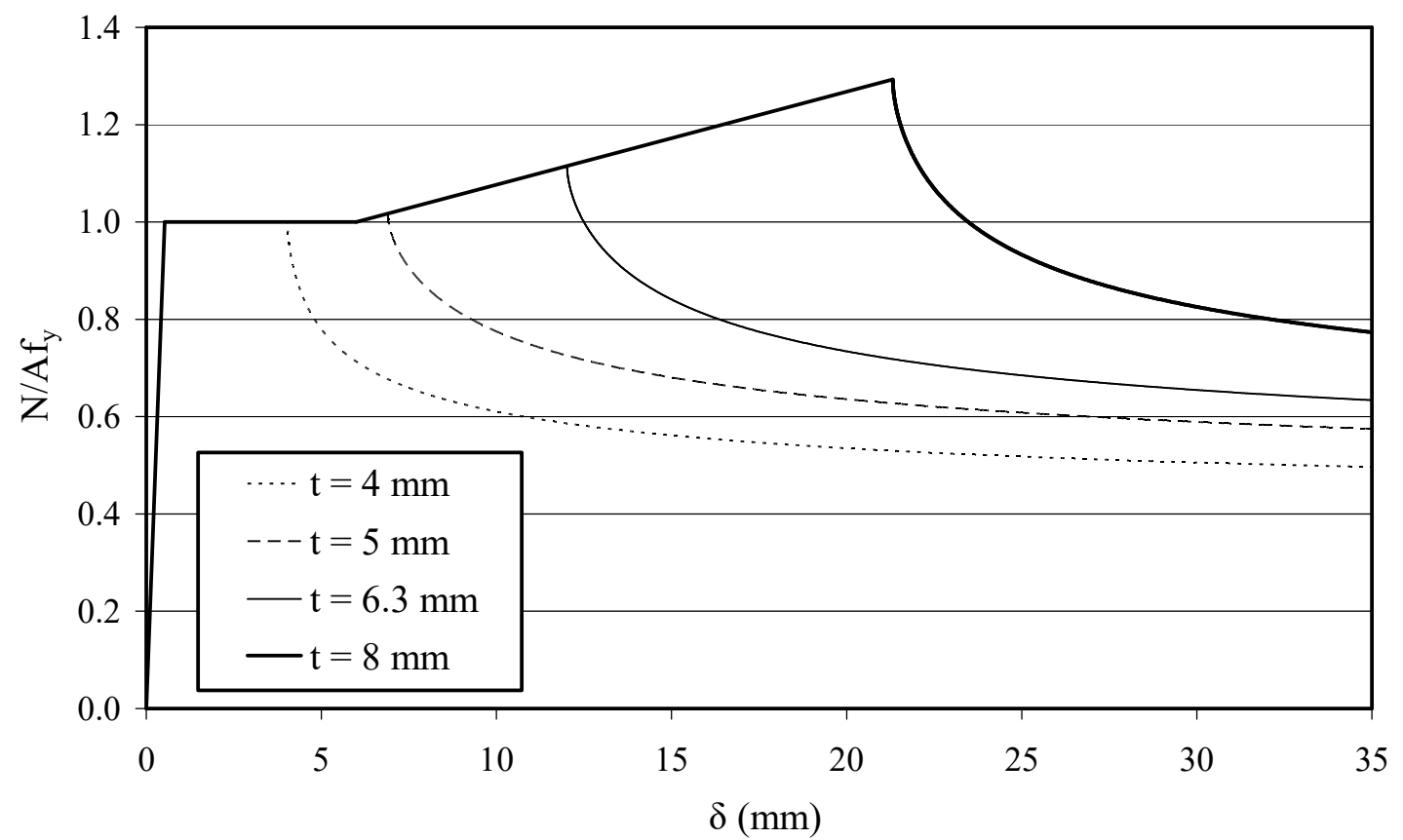

Figure 19. Analytical load-end shortening curves for $150 \times 75$ EHS of different thickness with $\mathrm{S}_{\mathrm{h}}(\Delta)$.

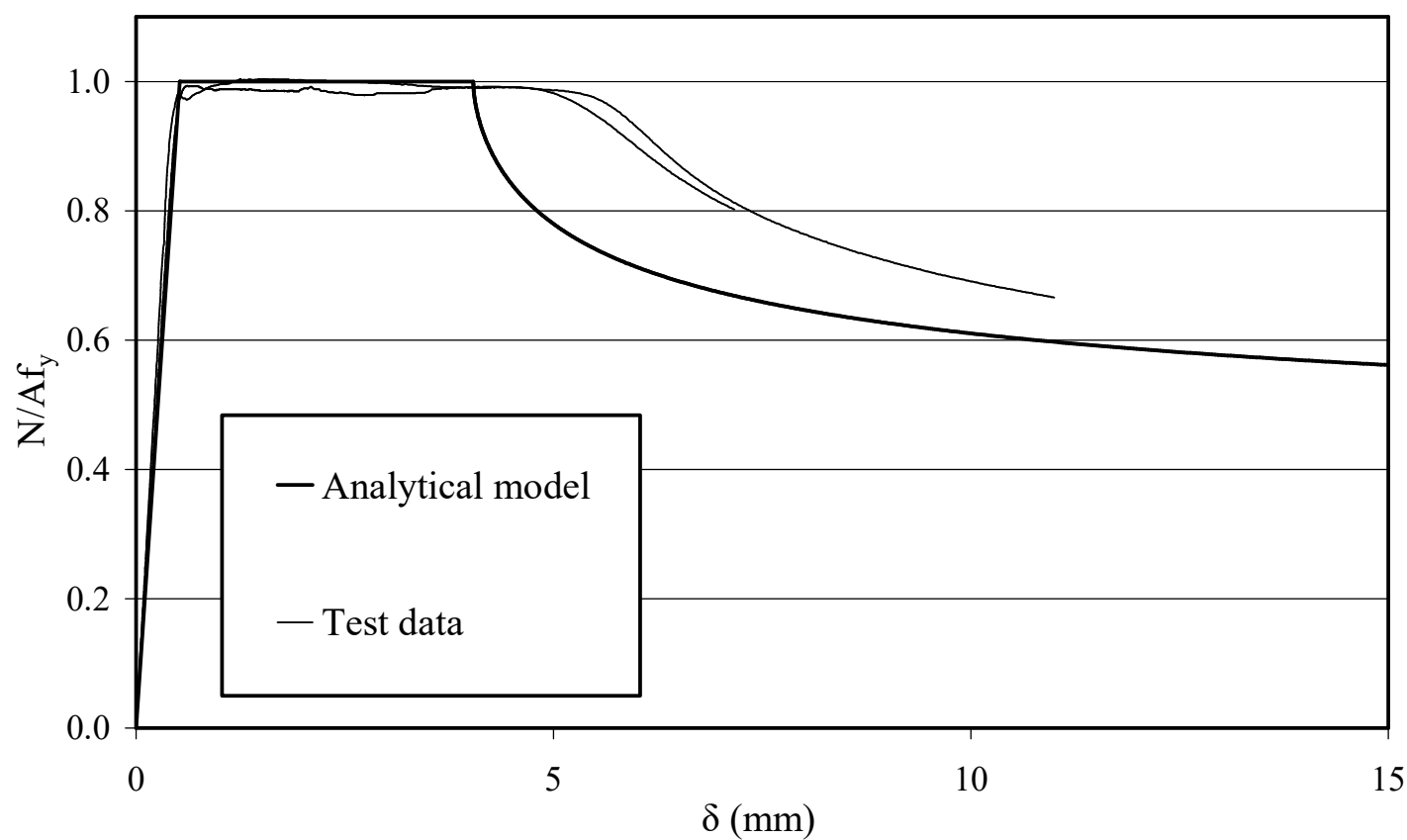

Figure 20. Comparison of load-end shortening curves from the analytical model with $\mathrm{S}_{\mathrm{h}}(\Delta)$ and two tests for $150 \times 75 \times 4$ EHS. 


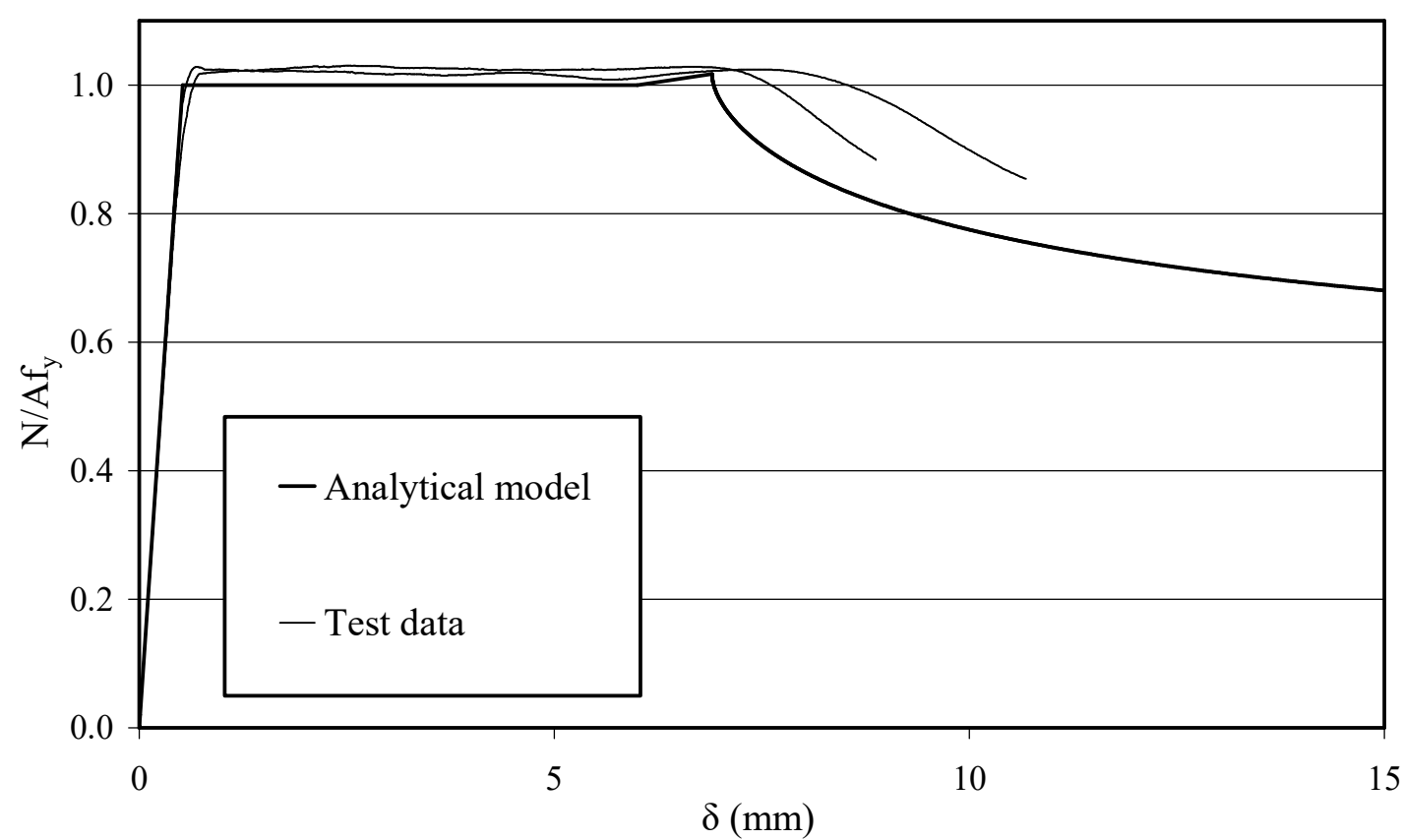

Figure 21. Comparison of load-end shortening curves from the analytical model with $\mathrm{S}_{\mathrm{h}}(\Delta)$ and two tests for $150 \times 75 \times 5$ EHS.

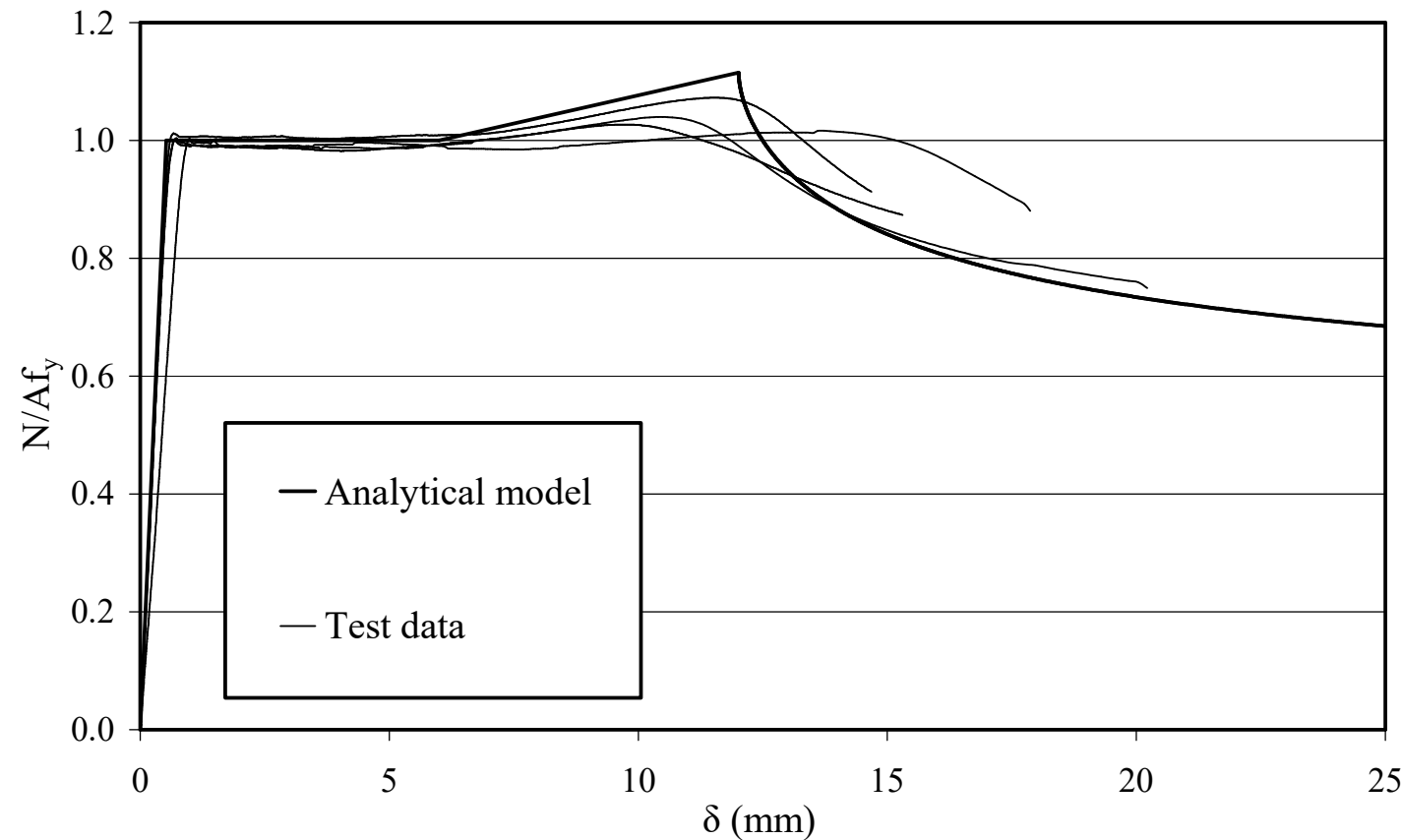

Figure 22. Comparison of load-end shortening curves from the analytical model with $\mathrm{S}_{\mathrm{h}}(\Delta)$ and four tests for $150 \times 75 \times 6.3$ EHS. 


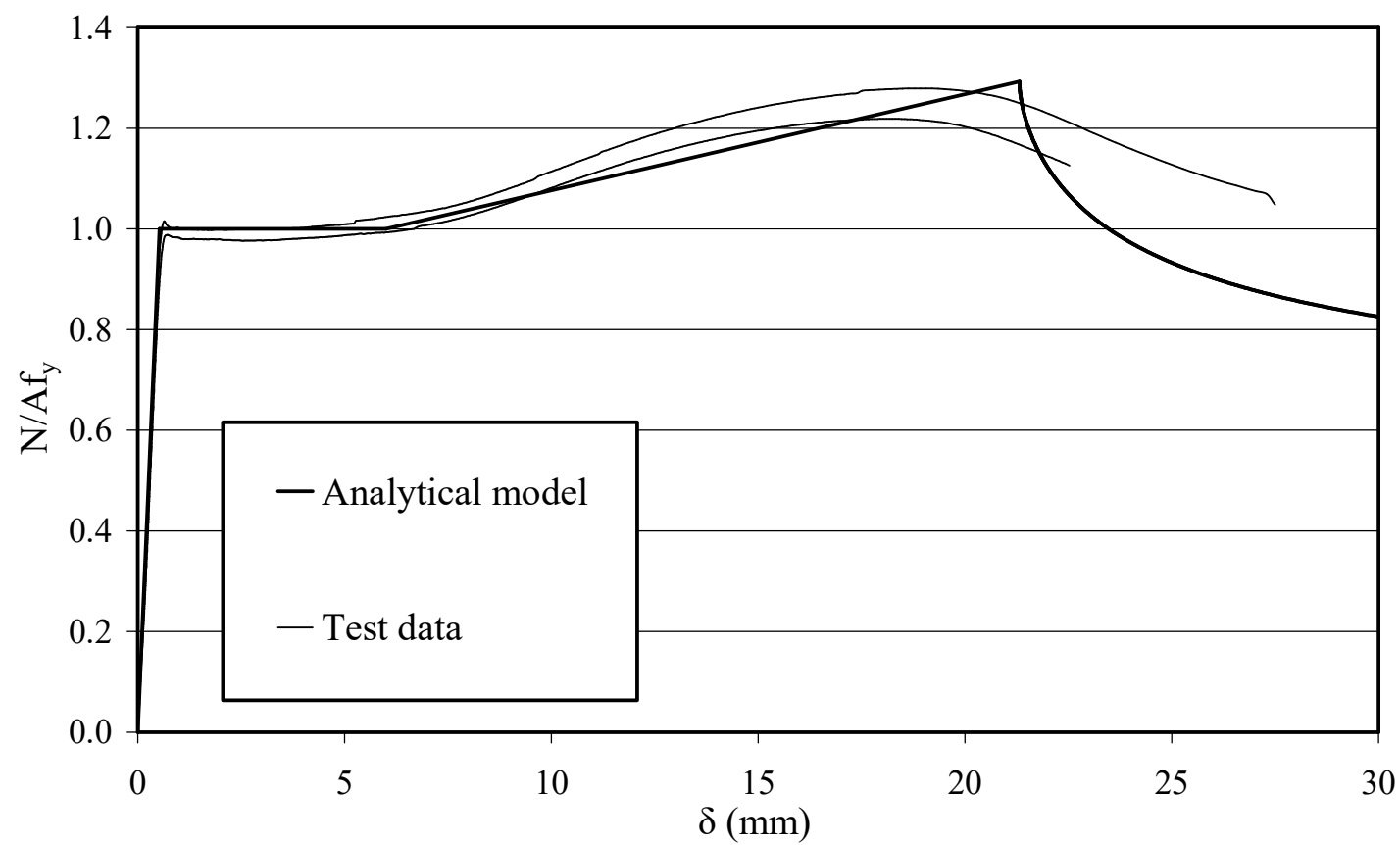

Figure 23. Comparison of load-end shortening curves from the analytical model with $\mathrm{S}_{\mathrm{h}}(\Delta)$ and two tests for $150 \times 75 \times 8$ EHS. 